\title{
Crack band theory for fracture of concrete
}

\author{
Zdeněk P. Bažant \\ Northwestern University, Evanston, Illinois, 60201. \\ B. H. On \\ Graduate Student, Dept. of Civil Engineering, Northwestern University, Evanston, Illinois, 60201.
}

Active Member of RILEM. Professor of Civil Engineering and Director, Center for Concrete and Geomaterials, The Technologic:: 1:5sicite,

A fracture theory for a heterogeneous aggregate material which exhibits a gradual strainsoftening due to microcracking and contains aggregate pieces that are not necessarily small compared to structural dimensions is developed. Only Mode I is considered. The fracture is modeled as a blunt smeared crack band, which is justified by the random nature of the microstructure. Simple triaxial stress-strain relations which model the strain-softening and describe the effect of gradual microcracking in the crack band are derived. It is shown that it is easier to use compliance rather than stiffness matrices and that it suffices to adjust a single diagonal term of the compliance matrix. The limiting case of this matrix for complete (continuous) cracking is shown to be identical to the inverse of the well-known stiffness matrix for a perfectly cracked material. The material fracture properties are characterized by only three parameters - fracture energy, uniaxial strength limit and width of the crack band (fracture process zone), while the strain-softening modulus is a function of these parameters. A method of determining the fracture energy from measured complete stressstrain relations is also given. Triaxial stress effects on fracture can be taken into account. The theory is verified by comparisons with numerous experimental data from the literature. Satisfactory fits of maximum load data as well as resistance curves are achieved and values of the three material parameters involved, namely the fracture energy, the strength, and the width of crack band front, are determined from test data. The optimum value of the latter width is found to be about 3 aggregate sizes, which is also justified as the minimum acceptable for a homogeneous continuum modeling. The method of implementing the theory in a finite element code is also indicated, and rules for achieving objectivity of results with regard to the analyst's choice of element size are given. Finally, a simple formula is derived to predict from the tensile strength and aggregate size the fracture energy, as well as the strain-softening modulus. A statistical analysis of the errors reveals a drastic improvement compared to the linear fracture theory as well as the strength theory. The applicability of fracture mechanics to concrete is thus solidly established.

\section{INTRODUCTION}

The structural size effect is the central problem in predictions of fracture. Fracture tests are normally conducted on relatively small specimens, and fracture theories are usually verified in the laboratory by testing relatively small beams or panels. In practice, we then dare to extrapolate this information to structures which are of ten far larger than anything tested. This, of course, cannot be done reliably without a sound, realistic fracture theory.
For the initiation of cracks in a body without -cks and stress concentrations, the concept of stre, is is acceptable. Not so, however when a sharp crack tady exists. The elastic analysis then yields infinite stross at the crack front, and the strength criterion inceractly predicts the crack to extend at an infinitely smal oad. When a finite element mesh is refined, the load needed to reach the strength limit strongly depends ot the choice of element size and incorrectly converges to zero. Thus, the elastic finite element analysis of cracking based on the strength criterion, as currently used in 

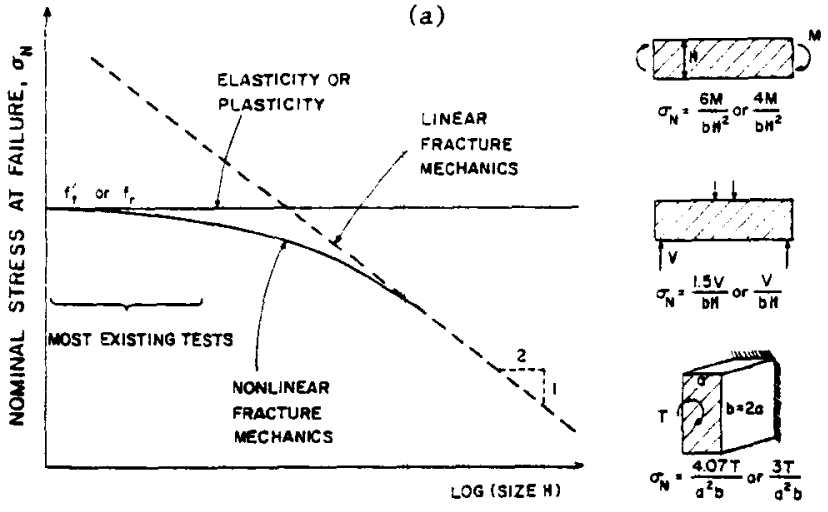

(b)

(c) Metais
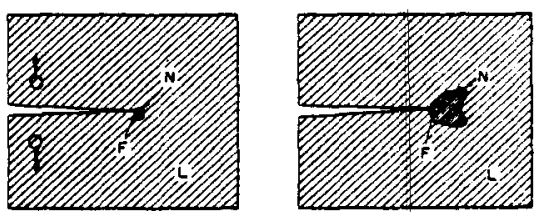

(d) Concrele

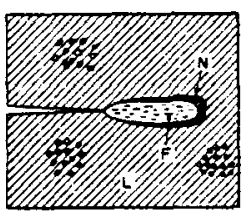

Fig. 1. - (a) Illustration of structural size effect in failure; $(b-d)$ Relative sizes of fracture process zone (F), nonlinear hardening zone (N) and linear zone (L).

computer codes, is unobjective in that it strongly depends on the analyst's choice of mesh. Neglect of the infinite stress concentration at the crack front, e.g., when the bending theory is applied to the ligament section, does not make the strength criterion correct. This may be illustrated in figure $1 a$ where we consider any type of geometrically similar specimens or structures of various sizes, with geometrically similar cracks, and plot the logarithm of the nominal stress $\sigma_{N}$ at failure (calculated e.g., by applying the bending theory to the ligament) versus the logarithm of the size. The strength criterion predicts $\sigma_{v}$ at failure to be independent of size, while all tests indicate a decrease of $\sigma_{N}$ with an increase in size.

These difficulties can be circumvented only by fracture mechanics, in which the basic criterion is that of energy release needed to create the crack surface. According to the classical linear fracture mechanics [30], $\sigma_{N}$ in figure $1 a$ is then proportional to (size) ${ }^{-1 / 2}$, i.e., the plot of $\log \sigma_{N}$ versus $\log$ (size) is a straight line of downward slope $-1 / 2$ (fig. $1 a$ ). However, with the exception of very large structures, this slope appears to be too steep in comparison with most existing test data [49]. The reality seems to be a gradual transition from the horizontal straight line for the strength criterion to the inclined straight line of slope $-1 / 2$ ( $f$ ig. $1 \mathrm{a}$ ). Failure analysis in this transition range is more difficult than it is for the limiting cases of strength criterion or linear fracture mechanics, and most concrete structures unfortunately fall in this category. In the work which follows (based on report [10]), we develop a similified theory which appears to give realistic results over the complete range of sizes, including the transition range, and can be brought in a good agreement with essentially all available fracture test data for concrete, a goal not yet achieved in the existing literature.

The reason for the deviations from linear fracture mechanics observed in concrete (as well as rocks) consists in its heterogeneity of the material, causing that it behaves nonlinearly within a relatively large zone adjacent to the fracture front, while the linear fracture mechanics requires this zone to be small. This behavior is similar to ductile fracture of metals [40], but there is one significant difference. The fracture process zone, representing that part of the nonlinear zone in which the material undergoes progressive microcracking manifested by strain-softening (a decrease of stress at increasing strain) [18], is still usually small in ductile fracture of metals, but in concrete it is often very large (compared to the cross section of the structure), due to the large size of aggregate ( $f$ ig. $1 b-d$ ). For this reason, the non linear fracture theories developed for metals cannot be indiscriminately transplanted to concrete. Furthermore, since the plastic deformation of concrete in tension is negligible and the strain-softening in a tensile test [18] is not preceded by a horizontal plateau, the boundary of the fracture process zone may be considered to be nearly identical to the boundary of the nonlinear zone, whereas in metals these boundaries are far apart ( fig. $1 c, d$ ). Thus, it appears that we do not need to analyse fracture by means of the $J$-integral, and can directly use the fracture energy of the crack band. The $J$-integral is, anyway, inapplicable for contours inside the strain-softening region, and for contours within the linear exterior region it reduces to the fracture energy.

Because of computational convenience as well as resemblance to reality, the cracking of concrete (and also rock) has long been modeled in large finite element programs as systems of parallel crack that are continuously distributed (smeared) over the finite elements, as introduced by Rashid ( $c f$. Ref. [1]). As the cracking criterion, the strength has been used. It was shown, however, that the strength concept is unobjective in that the results of analysis can be strongly affected by the analyst's choice of finite element size $[6,7,16]$. A remedy is to use as the cracking criterion the fracture energy. This concept was worked out in detail for the case when the stress can be assumed to drop suddenly to zero as the fracture forms $[5-7,16]$. The assumption of an abrupt stress drop is, however, inadequate for cross section dimensions that are not sufficiently large compared to the aggregate size. In this case a gradual strain-softening due to progressive microcracking must be considered, and extension of the previous work $[6,7,16]$ to cover this case will be the purpose of this study, which is based on a 1981 report [10].

We restrict our attention to Mode I cracks, i.e., cracks (straight or curved) which have no shear stress at their front. This does not detract much from practical usefulness since cracks in concrete seem to propagate in most situations along such a path that Mode I prevails at the front. 


\section{THE HYPOTHESLS OF BLUNT CRACK BAND}

Central to the analysis which follows is the hypothesis that fracture in a heterogeneous material can be modeled as a band of parallel, densely distributed microcracks with a blunt front. This hypothesis may be justified as follows.

\section{Justification I. Representative volume}

When a heterogeneous material is approximated by an equivalent homogeneous continuum (without couple stresses), as is standard for concrete structures, one must distinguish the continuum stresses and strains (macrostresses and macrostrains) from the actual stresses and strains in the microstructure, called the microstresses and microstrains. In the theory of randomly inhomogeneous materials, the equivalent continuum stresses and strains are defined as the averages of the microstresses and microstrains over a certain representative volume. The cross section of this volume should ideally be taken to be much larger than the size of the inhomogeneities, and even for a crude modeling must be considered to be at least several times their size, i. e., several times the maximum aggregate size in case of concrete.

Consequentiy, in the usual analysis, in which only the average elastic (or inelastic) material properties are considered and the geometry of the microstructure with the differences in the elastic constants between the aggregate and the cement paste is not taken into account, the distribution of stress or strain over distances less than several aggregate sizes has no physical meaning. Only the stress resultants and the accumulated strain over the cross section of the characteristic volume do. In the finite element context, this means, therefore, that it makes no sense to use finite elements smaller than several aggregate sizes (and also that it makes no sense to use in such smallest finite elements distribution functions of higher order). In case of fracture, this further means that if an equivalent homogeneous continuum is assumed, it makes no sense to consider concentrations of stress (or of microcrack density) within volumes less than several aggregate sizes. A similar conclusion follows when we realize that the actual crack path in concrete is not smooth but highly tortuous. Since the crack tends to pass around the hard aggregate pieces and randomly sways to the side of a straight path by distances roughly equal to the aggregate size, again the actual stress (microstress) variation over such distances can be relevant for the macroscopic continuum model.

According to the foregoing justification, one should not attempt to subdivide the width of the crack band front into several finite elements. There is however also another reason. The strain-softening continuum is unstable and a strain localization instability, in which the deformation would localize into one of the elements in the subdivision, would take place.

\section{Justification II. Equivalence of results}

For an elastic material in which the stress drops suddenly to zero at the fracture front, it was found $[5,16]$ that a sharp interelement crack and a smeared crack band give essentially the same results for the energy release rate and agree closely (within a few percent) with the exact elasticity solution, provided that the finite element is not larger than about $1 / 15$ of the cross section dimension (square meshes without any singularity elements were used). This is true regardless of the aggregate size.

To demonstrate it here, figure 3 shows some of the numerical results for a line crack (left) and crack band (right) extracted from Reference [5]. The finite element mesh covers a cut-out of infinite medium loaded at infinity by uniform normal stress $\bar{\sigma}$ perpendicular to a line crack of length $2 a$. The nodal loads applied at boundary are calculated as the resultants (over the element width) of the exact stresses in infinite medium at that location. The solid curve is Westergaard's exact solution. The calculated points are given for the square mesh shown (mesh $A$ ), as well as meshes $B$ and $C$ (not shown) with elements reduced to $1 / 2$ and to $3 / 8$. (Each element consisted of 2 constant -strain triangles, and calculations were mare for $\bar{\sigma}=0.981 \alpha(\mathrm{MPa})$, $E_{\mathrm{c}}=2256 \mathrm{MPa}, \nu=0.2$, and stress intensity factor $0.6937 \mathrm{MNm}^{-3 / 2}$.)

The same equivalence of line cracks and crack bands may be expected when a gradual stress drop is considered (and fig. 5 confirms it). The reason for this equivalence is the fact that fracture propagation depends essentially on the flux of energy into the fracture process zone at the crack front, and this flux is a global characteristic of the entire structure, depending little on the details of the stress and strain distributions near the fracture front.

Furthermore, the fact that the results for the stress intensity factor [30] obtained with nonsingular finite elements agree closely (within $1 \%$ for typical meshes) with the exact elasticity solution also confirms that there is no need to use singularity elements for fracture analysis. In any event, the non-uniform stress distribution implied in a singularity element is meaningiul only if its size is many times the representative volume, i. e., at least 20-times the aggregate size, which is too large for most applications.

\section{Computational advantages}

Since the line crack and the crack band models are essentially equivalent, the choice of one or the other is basically a question of computational effectiveness. From this viewpoint, the line crack model appears to be disadvantageous. When the crack extends through a certain node, the node must be split into two nodes, increasing the total number of nodes and changing the topological connectivity of the mesh. Uniess all nodes are renumbered, the band structure of the structural stiffness matrix is destroyed. All this complicates 


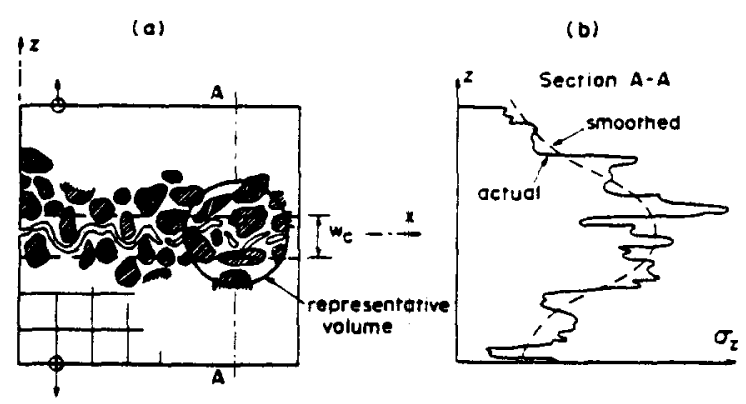

(c)
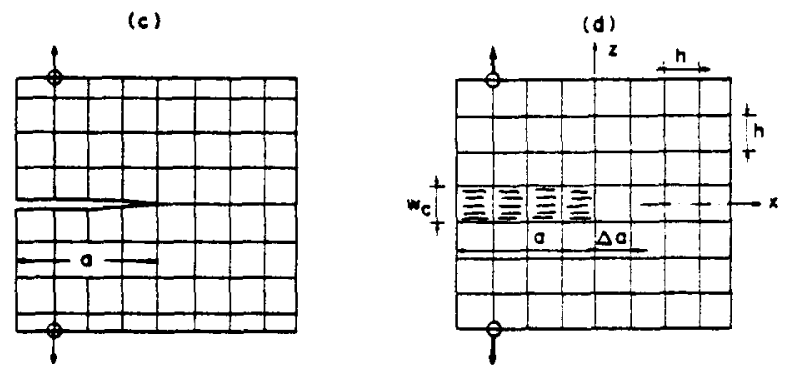

F. 2 - (a) Actual crack morphology, (b) Actual stresses and thetr smoothing, (c) Line crack model, $(d)$ Crack band model used here.

programming. When the direction in which a Mode I crack should extend is not known in advance, one must make calculations for various possible locations of the node ahead of the crack front, through which the crack should pass, in order to identify the location for which the energy release rate is maximum.

These difficulties are avoided by the crack band model. Here the crack is modeled by changing the isotropic elastic moduli matrix to an orthotropic one, reducing the material stiffness in the direction normal to the cracks in the band. This is easily implemented in a finite element program, regardless of the direction of the crack with respect to the mesh lines. A Mode I crack propagating in an arbitrary direction with respect to the mesh lines, or a Mode I crack following a curved path, may be easily modeled as a zig-zag crack band (see fig. $4 e$ ) whose overall direction in the mesh approximates the actual crack direction. (Numerical applications for skew, curved or asymmetric cracks are however beyond the scope of this study.)

A further advantage of the crack band model is that the information obtained in studies of stress-strain relations and failure envelopes can be applied to fracture (e.g., the effect of the compressive normal stress parallel to the crack). Still another advantage is the fact that with the crack band model one can treat the case when principal stress directions in the fracture process zone rotate during the progressive fracture formation, i.e., during the strain-softening. This case arises, e.g., when first a vertical tensile normal stress produces only a partial cracking, and failure is subsequently caused by horizontal shear stresses. The line crack models do not seem suited to handle this situation.

\section{Actual pattern of microcracks}

Recently, various measurements are being made to observe the formation of microcracks at the fracture front $[37,41]$. From these observations it seems that the larger microcracks that can be seen are not spread over a band of a large width but are concentrated essentially on a line. However, the line along which the microcracks are scattered is not straight (or smoothly curved) but is highly tortuous ( fig. 2), deviating to each side of the
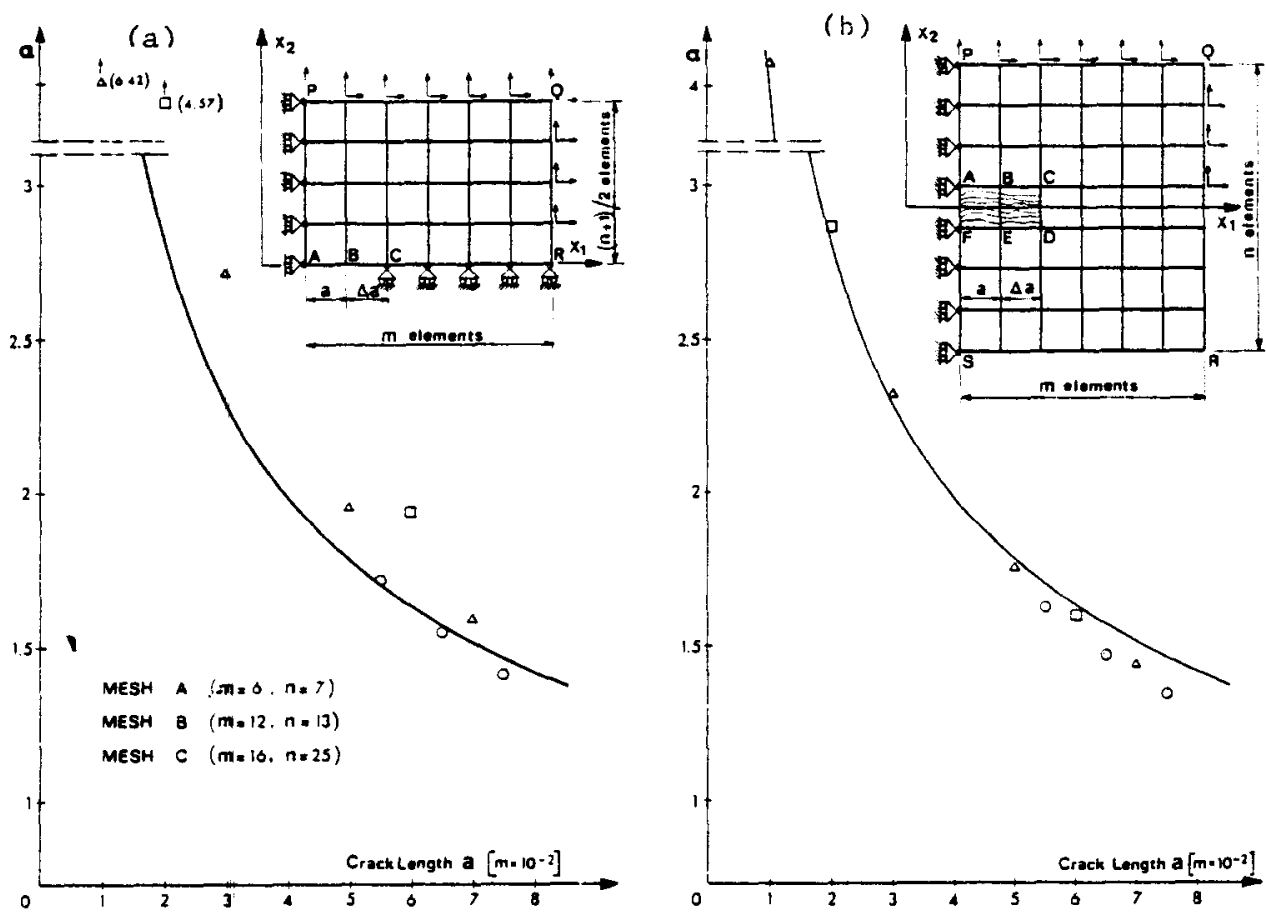

Fig. 3. - Finite element results for crack band (right) and for line crack (left), compared to exact linear fracture mechanics solution (after Bazant-Cedolin, 1979, Ref. [5]). 
(a)
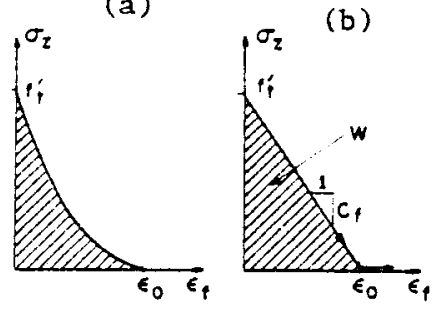

(e)

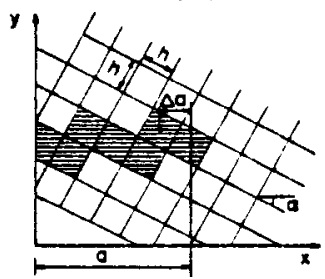

(c)

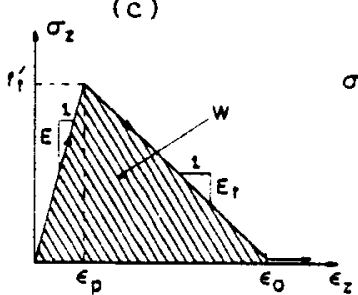

(d)

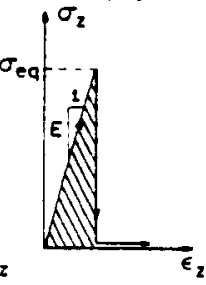

(f)

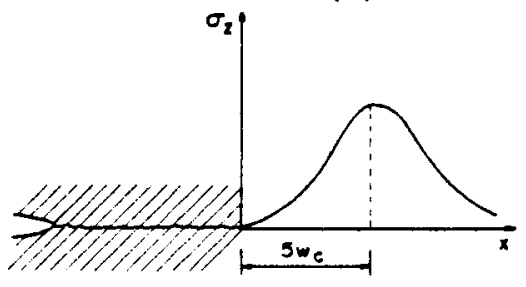

(g)
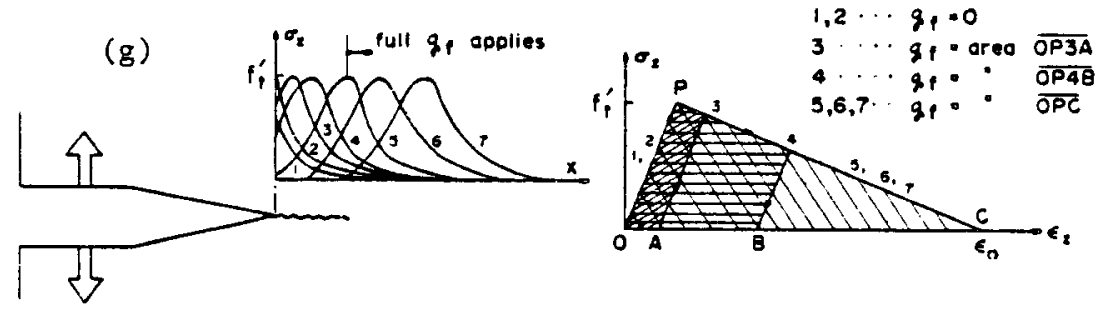

Fig. 4 - $-(a-d)$ Stress-strain diagrams for fracture process zone; $(e)$ Zig-zag crack band; $(f-g)$ Stress distributions in fracture process zone.

straight line extension by a distance equal to about the aggregate size, as the crack is trying to pass around the harder aggregate pieces. In the equivalent, smoothed macroscopic continuum which is implied in structural analysis, the scatter in the locations of visible microcracks relative to a straight line is characterized by a microcrack band better than by a straight row of microcracks.

At the same time, we should realize that the boundary of the fracture process zone should not be defined as the boundary of visible microcracks but as the boundary of the strain-softening region, i. e., the region in which the maximum stress decreases with increasing maximum strain. Since the strain-softening is caused not only by microcracking but also by any bond ruptures, the fracture process zone could be much wider (as well as longer) than the region of visible microcracks.
These questions are, however, unimportant for the macroscopic continuum modeling because of the foregoing Justifications I and II. They would matter only for micromechanics analysis, aimed, e.g., at calculating the fracture energy from the constituent properties and geometry of the microstructure.

\section{Previous works}

According to Justifications I and II, it cannot make much difference whether the fracture is modeled as a line crack (a sharp interelement crack) or as a band of continuously distributed (smeared) parallel cracks. Thus, if the relation of the normal stress $\sigma_{z}$ and the relative displacement $\delta_{f}$ across a line crack is identical to the relation of $\sigma_{z}$ to the displacement $\delta_{f}=\varepsilon_{f} w_{c}$ obtained by accumulating the strains $\varepsilon_{f}$ due to
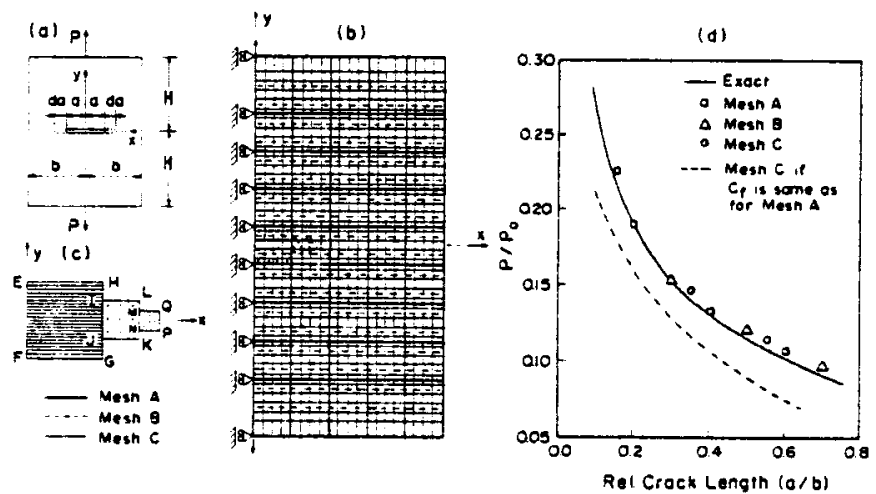

Fig. 5. - (a) Center-cracked plate; (b) Finite element mesh refinements; (c) Crack front for mesh $A$, B, and $C_{;}$(d) Comparison of numerical results. 
microcracking over the width $w_{c}$ of the crack band, the line crack model and the crack band model are essentially equivalent (except for the influence of lateral stresses $\sigma_{x}$ and $\sigma_{y}$ in the crack band model). Line crack models with sof tening stress-displacement relations were proposed in many previous works $[2,8,20,27,29,51]$. These include the works of Knauss [29], Wnuk [51], and Kfouri, Miller and Rice $[27,28]$ on polymers and metals, which considered a gradual release of the forces between the opposite surfaces as the opening displacements grow, as well as the finite element equivalent of a gradually decreasing internodal force as one node in a finite element grid is being separated by fracture into two nodes. For concrete, this concept of a gradually decreasing stress-displacement relation was first applied in the outstanding original work of Hillerborg, Modéer and Peterson $[20,41]$ in their model of a fictitious sharp interelement crack, which provided inspiration for this work.

\section{PROGRESSIVE CRACKING AND FRACTURE PROCESS ZONE}

We will work with a system of cartesian coordinate axes $x_{1}=x, x_{2}=y, x_{3}=z$ and will treat concrete as an isotropic elastic material characterized by Young's modulus $E$ and Poisson ratio v. Consider that a system of densely and uniformly distributed discontinuous microcracks normal to axis $z$ develops in the material while the stresses are kept constant. This must lead to an increase of strain $\varepsilon_{z}$, but the effect of this on strains $\varepsilon_{x}, \varepsilon_{y}$ parallel to the microcracks should be nil. Then, assuming that $\sigma_{x}, \sigma_{y}, \sigma_{z}$ are the principal stresses and $\varepsilon_{x}, \varepsilon_{y}, \varepsilon_{z}$ are the principal strains, we have:

$$
\left\{\begin{array}{l}
\varepsilon_{x} \\
\varepsilon_{y} \\
\varepsilon_{z}
\end{array}\right\}=\left[\begin{array}{cccc}
1 & -v & -v \\
\frac{1}{E} & -v & 1 & -v \\
& -v & -v & 1
\end{array}\right]\left\{\begin{array}{l}
\sigma_{x} \\
\sigma_{y} \\
\sigma_{z}
\end{array}\right\}+\left\{\begin{array}{l}
0 \\
0 \\
\varepsilon_{f}
\end{array}\right\},
$$

where $\varepsilon_{f}$ is the fracture strain, i. e., the additional strain caused by the opening of the microcracks, $E=$ Young's elastic modulus of concrete, and $v=$ its Poisson's ratio $(\simeq 0.18)$.

As generally accepted, the front of an advancing crack band (microcrack zone), called also the fracture process zone, has a certain characteristic width $w_{c}$ ( fig. 2). This width could, in principle, be determined by stability analysis [3], although in practice we do not quite know yet how to carry out such analysis. For plain concrete, we may consider $w_{c}$ as a material constant that can be determined by experiment. We expect that $w_{c}$ is several-times the maximum aggregate size. Now, the meaning of $\varepsilon_{f}$ is the average over the fracture process zone of the deformation due to microcracking, precisely $\varepsilon_{f}=\delta_{f} / w_{c}$ where $\delta_{f}=\sum_{i} \delta_{f}^{i}=$ sum of the openings of individual microcracks intersecting axis z ( fig. 2).

Neglecting rate effects (time effects), it is probably reasonable for us to assume that $\varepsilon_{f}$ is a function of $\sigma_{z}$, i. e., $\varepsilon_{f}=f\left(\sigma_{z}\right)$. Obviously, it must be a monotonically decreasing function ( fig. $4 a, b$ ).

The simplest choice is a linear function, i. e. :

$$
\varepsilon_{f}=f\left(\sigma_{z}\right)=\frac{1}{C_{f}}\left(f_{t}^{\prime}-\sigma_{z}\right)
$$

As we will see, this choice suffices to get satisfactory agreement with all available test data. Here $f_{t}^{\prime}$ is the peak uniaxial stress, or tensile strength.

Substituting Equation 2 into Equation 1 we obtain, for the strain-softening range:

$$
\left\{\begin{array}{l}
\varepsilon_{x} \\
\varepsilon_{y} \\
\varepsilon_{z}
\end{array}\right\}=\left[\begin{array}{ccc}
E^{-1} & -v E^{-1} & -v E^{-1} \\
& E^{-1} & -v E^{-1} \\
\text { sym. } & & E_{p}^{-1}
\end{array}\right]\left\{\begin{array}{l}
\sigma_{x} \\
\sigma_{y} \\
\sigma_{z}
\end{array}\right\}+\left\{\begin{array}{c}
0 \\
0 \\
\varepsilon_{0}
\end{array}\right\},
$$

in which

$\frac{1}{E_{t}}=\frac{1}{E}-\frac{1}{C_{f}} \leqq 0$,

$E_{t}$ is the tangent softening modulus of the declining (strain-softening) segment of the uniaxial stress-strain diagram in the $z$ direction ( fig. 4); and $\varepsilon_{0}$ is the strain at the end of strain-softening ( fig. 4), at which the microcracks coalesce into a continuous crack and $\sigma_{z}$ vanishes; $\varepsilon_{0}=f_{t}^{\prime} / C_{f}$; the square matrix in Equation 3 is the tangent compliance matrix.

For finite element analysis, Equation 3 must be inverted to get the stiffness matrix. This matrix is particularly simple for the case of plane stress analysis $\left(\sigma_{y}=0\right)$; in this case the inversion of Equation 3 yields:

$\left\{\begin{array}{l}\sigma_{x} \\ \sigma_{z}\end{array}\right\}=\left[\begin{array}{cc}E+v^{2} E_{t}^{\prime} & v E_{\mathrm{r}}^{\prime} \\ v E_{t}^{\prime} & E_{\mathrm{t}}^{\prime}\end{array}\right]\left\{\begin{array}{c}\varepsilon_{x} \\ \varepsilon_{z}-\varepsilon_{0}\end{array}\right\}$,

in which $E_{t}^{\prime}=\left(E^{\prime-1}-C_{f}^{-1}\right)^{-1}, E^{\prime}=E /\left(1-v^{2}\right)$.

Let us now consider general initial elastic properties which may possibly be anisotropic (e.g., when the present theory is applied to rock; see Ref. [3]). Assuming that the directions of principal stresses and principal strains coincide, uncracked concrete is then characterized by the stress-strain relation $\underline{\varepsilon}=\underset{\sim}{\sigma} \sigma$ in which $\underset{\sim}{\varepsilon}=\left(\varepsilon_{x}, \varepsilon_{y}, \varepsilon_{z}\right)^{T}, \underset{\sim}{\sigma}=\left(\sigma_{x}, \sigma_{y}, \sigma_{z}\right)^{T}, \underset{\sim}{C}=(3 \times 3)$ compliance matrix, and superscript $T$ denotes the transpose of a matrix. Since the effect of the formation of microcracks normal to $z$ consists in an increase of $\varepsilon_{z}$ at constant $\varepsilon_{y}$, $\varepsilon_{x}$ and constant stresses, the secant compliance 
formulation of the stress-strain relation may generally be written in the form $\underset{\sim}{\varepsilon}=\underset{\sim}{\mathrm{C}}(\mu) \underset{\sim}{\sigma}$ or:

$$
\left\{\begin{array}{l}
\varepsilon_{x} \\
\varepsilon_{y} \\
\varepsilon_{z}
\end{array}\right\}=\left[\begin{array}{ccc}
C_{11} & C_{12} & C_{13} \\
& C_{22} & C_{23} \\
\text { sym. } & & C_{33} \mu^{-1}
\end{array}\right]\left\{\begin{array}{l}
\sigma_{x} \\
\sigma_{y} \\
\sigma_{z}
\end{array}\right\}
$$

where $C_{11}, C_{12}, \ldots, C_{33}$ are the initial elastic compliances before cracking, and $\mu$ is a cracking parameter which may, in general, depend on stress and strain and varies within the range $0<\mu<1$. For $\mu=1$ we have an uncracked material. Equation 6 becomes equivalent to Equation 3 if the relation $\varepsilon_{z}=E_{t}^{-1} \sigma_{z}+\varepsilon_{0}$ becomes equivalent to the relation $\varepsilon_{z}=C_{33} \mu^{-1} \sigma_{z}$ where $C_{33}=E^{-1}$. This occurs if we set $E^{-1} \mu^{-1}=E_{\ell}^{-1}+\varepsilon_{0} / \sigma_{z}$ or:

$$
\frac{1}{\mu}=E\left(\frac{\varepsilon_{0}}{\sigma_{z}}+\frac{1}{E_{t}}\right)=\frac{E}{-E_{t}} \frac{\varepsilon_{z}}{\varepsilon_{0}-\varepsilon_{z}}
$$

in which $E, E_{\mathrm{q}}$ and $\varepsilon_{0}$ are constants, and $\sigma_{z}$ and $\varepsilon_{z}$ are variables. Note that $\mu \rightarrow 0$ as the state of continuous cracks is approached, i. e., as $\sigma_{z} \rightarrow 0$ (or $\varepsilon_{z} \rightarrow \varepsilon_{0}$ ). Cracking starts when $\sigma_{z}=f_{t}^{\prime}=C_{f} \varepsilon_{0}$, and substituting this into Equation 6 along with Equation 4, we verify that $\mu=1$ corresponds to the start of cracking.

A salient and simple feature of our formulation is the independence of the Poisson effect from the microcracking, reflected by the fact that the offdiagonal terms in Equation 3 are not affected by microcracking. This is contingent upon our assumption that all microcracks are normal to axis $z$. This assumption contrasts with that implied in the plasticfracturing theory [9] - a theory intended mainly for compressive or shear loadings. Due to the adoption of isotropic treatment of the elastic part of the deformation, that theory implies the microcracks to be oriented randomly. Then, of course, the microcracking in that theory does influence the Poisson effect.

A gradually declining stress-strain relation for concrete, as opposed to a sudden stress drop, was previously introduced in a program for dynamic cracking for numerical reasons [35]. In dynamics, a sudden stress drop emits through the finite element mesh shock waves which are of spurious nature.

It should be noted that our treatment of progressive microcracking by reducing the stiffness with a multiplicative parameter (as in Equation 6) is quite similar to the so-called continuous damage mechanics $[23,24,33,34,36]$; but in contrast to the existing works on this approach, we consider the damage concept to be inseparable from a zone of a certain characteristic width, $w_{c}$ (see Equation 16), or from an energy criterion (see Equations 14 and 20). Otherwise, predictions of continuous damage mechanics would depend on the choice of finite element size. same as they do for the strength criterion [7]. Also, our treatment of damage is anisotropic, while the existing works on continuous damage mechanics of concrete are confined to isotropic (scalar) representations of damage.

\section{STIFFNESS AND COMPLIANCE MATRICES FOR FULLY CRACKED MATERIAL}

According to our preceding considerations, the compliance matrix for the fully cracked concrete is obtained as $\lim \underset{\sim}{\underset{ }{C}}(\mu)$ for $\mu \rightarrow 0$ where $\underset{\sim}{\underset{C}{(}}(\mu)$ is given in Equation 6 . The behavior of fully cracked concrete is, however, normally described in terms of a stiffness matrix, the form of which is well known [46], and generally accepted as correct. We must therefore check that the inverse of $\lim \underline{C}(\mu)$ coincides with this stiffness matrix.

First we need to show the derivation of the wellknown stiffness matrix for concrete intersected by continuous cracks normal to $z$. To this end, it is convenient to first rewrite the elastic stiffness relation $\underset{\sim}{\sigma}=\underset{\sim}{D} \underset{\sim}{\varepsilon}$, in which $\underset{\sim}{D}=(3 \times 3)$ elastic moduli (stiffness) matrix, in a partitioned form:

$\left\{\begin{array}{c}\sigma^{a} \\ \sigma_{z}\end{array}\right\}=\left[\begin{array}{cc}G & \underset{H}{H} \\ \tilde{H}^{T} & \tilde{D}_{33}\end{array}\right]\left\{\begin{array}{c}\varepsilon^{a} \\ \varepsilon_{z}\end{array}\right\}$

Consider now a material that is fully cracked in planes normal to $z$. Then we have $\sigma_{z}=0$, and Equation 8 is applicable provided that $\varepsilon_{z}$ is replaced with strain $\varepsilon_{z}^{s}$ of the solid concrete between the continuous cracks. So, from Equation 8, $0=\underset{\sim}{H^{T}} \underset{\sim}{\varepsilon^{a}}+D_{33} \varepsilon_{z}^{s}$ from which $\varepsilon_{z}^{s}=-{\underset{\sim}{H}}^{T} \underline{\sim}^{a} / D_{33}$. Furthermore, ${\underset{\sim}{\sigma}}^{a}=\underline{G} \tilde{\varepsilon}^{a}+\underset{\sim}{H} \xi_{z}^{s}$, and so $\sigma^{a}=\left(\tilde{G}-\underset{\sim}{H} \sim_{\sim}^{r} D_{33}^{-1}\right) \underset{\varepsilon^{a}}{q}$. This provides:

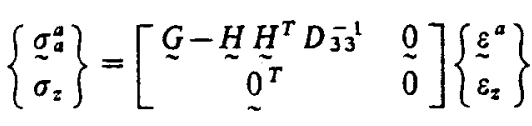

$$
\begin{aligned}
& \text { or } \quad \underline{\sigma}=\underline{\sim}^{f r} \underline{\varepsilon} \text {, }
\end{aligned}
$$

which may be written as:

$$
\begin{aligned}
\left\{\begin{array}{l}
\sigma_{x} \\
\sigma_{y} \\
\sigma_{z}
\end{array}\right\}=\left[\begin{array}{ccc}
D_{11}-D_{13}^{2} D_{33}^{-1} & D_{12}-D_{13} D_{23} D_{33}^{-1} & 0 \\
\text { sym. } & D_{22}-D_{23}^{2} D_{33}^{-1} & 0 \\
& & 0
\end{array}\right] \\
\left\{\begin{array}{l}
\varepsilon_{x} \\
\varepsilon_{y} \\
\varepsilon_{z}
\end{array}\right\}
\end{aligned}
$$

in which $D_{\alpha \beta}(\alpha, \beta=1,2,3)$ are the components of the initial stiffness matrix $\underline{D}$ for uncracked concrete, and 
$\underline{0}=(0,0)^{T}$. The stiffness matrix in Equation 10 was

given, e. g., by Rashid, and by Schnobrich et al. [46].

One can prove the following theorem (see Appendix I):

THEOREM I. - If $\underset{\sim}{C}=\underline{\sim}^{-1}$, then:

$\underline{D}^{\text {Sr }}=\lim _{\mu \rightarrow 0} \underline{C}^{-1}(\mu)$

This theorem confirms that the limit of our Equation 3 or 5 or 6 for partially cracked concrete is indeed equivalent to the well-known stiffness matrix for fully cracked concrete.

The compliance formulation of cracking, which we have just established (Equation 3 or 5 or 6), is simpler than the well-known stiffness formulation. In programming it suffices to modify a single term of the compliance matrix $\underset{\sim}{C}$, while in the stiffness formulation all terms of the matrix need recalculation. In case of complete cracking, one may not, of course, set in the program $\mu=0$; rather, one may assign a very large number to $\mu^{-1}$, e. g. $\mu^{-1}=10^{30}$. The main purpose of the compliance formulation is to allow description of both partially cracked and fully cracked concrete.

Equation 6 and 8-11 apply to generally anisotropic initial elastic properties. Except for possible stressinduced anisotropy (due, e. g., to high compressive stress parallel to cracks), we may treat concrete between the cracks as isotropic. Then:

$\underset{\sim}{\underset{C}{(}(\mu)}=\left[\begin{array}{cccc}1 & 1 & -v & -v \\ \hline E & -v & 1 & -v \\ & -v & -v & \mu^{-1}\end{array}\right]$,
$\stackrel{\sim}{f r}^{\prime r}=E^{\prime}\left[\begin{array}{lll}1 & v & 0 \\ \nu & 1 & 0 \\ 0 & 0 & 0\end{array}\right]$,

where $E^{\prime}=E /\left(1-v^{2}\right), E=$ elastic (Young's) modulus of concrete, $v=$ its Poisson ratio.

The incremental stress-strain relations, which are needed for step-by-step loading analysis, may be readily obtained by differentiating Equations 3 and 5 or 10 . Since our approximation of the stress-strain diagram is piecewise-linear, the incremental compliance and stiffness matrices are the same as those in Equations 3, 5, 9 and 10.

So far we paid no attention to those terms of the compliance or stiffness matrix which relate to shear stresses or shear strains and need to be set in a finite element program. For a symmetric fracture problem, which is the case for all Mode I fracture test specimens, the question of shear behavior in the fracture process zone is of no importance because the shear strains are zero due to symmetry. However, in general structural analysis, particularly when the crack band is curved or the loading is nonproportional, shear strains may be produced in the crack band after the crack initiation. In such a case, the compliance or stiffness matrix for the cracked material (a $6 \times 6$ enlargement of the matrices in Equations 3, 6 and 10) should reflect the aggregate interlock and the frictional-dilatant properties of rough cracks $[8,12]$.

Another related assumption implied in the use of a unique relation between total stresses and total strains is that of path-independence. This assumption is acceptable if the strains increase within the fracture process zone almost proportionally, which also implies that the principal strain directions do not rotate. Note that the same assumption underlies the method of $J$ integral in ductile fracture.

For the fracture process zone, however, consideration of a nonproportional strain increase, of a rotation of the principal stress directions, and of frictional shear seems to be often unimportant. This is because the angle of rotation of principal stress directions, or a change in strain ratios, of ten becomes large only after many loading steps; but it takes usually only a few loading steps for the fracture process zone to travel through a fixed point. It is for the same reason that the use of $J$-integral in ductile fracture met with so much success.

\section{FRACTURE CHARACTERISTICS}

The fracture energy, $\mathscr{G}_{f}$ is the energy consumed in the formation and opening of all microcracks per unit area of plane $(x, y)$. Thus:

$\mathscr{G}_{f}=w_{c} \int_{\sigma_{z}^{2}=f_{t}}^{0} \sigma_{z} d \varepsilon_{f}=\frac{1}{2} C_{f} \varepsilon_{0}^{2} w_{c}=\frac{f_{t}^{\prime 2}}{2 C_{f}} w_{c}$,

in which $w_{c}$ is the effective width of the fracture process zone (or crack band) over which the microcracks are assumed to be uniformly spread, and $f_{t}^{\prime}$ is the direct tensile strength. If $\mathscr{G}_{f}, f_{t}^{\prime}$ and $w_{c}$ are known from measurements, then the basic parameters of our stressstrain relation may be calculated as:

$C_{f}=\frac{f_{t}^{\prime 2} w_{c}}{2 \mathscr{G}_{f}}, \quad \varepsilon_{0}=\frac{f_{t}^{\prime}}{C_{f}}=\frac{2 \mathscr{G}_{f}}{f_{\mathrm{t}}^{\prime} w_{c}}$.

It is interesting to note that Equation 4 allows us to link the area $W$ under the complete uniaxial stressstrain diagram with the fracture energy. Substituting for $C_{f}$ from Equation 13, Equation 4 becomes $E_{\mathrm{t}}^{-1}=E^{-1}-2 \mathscr{G}_{f} / f_{\mathrm{t}}^{\prime 2} w_{c}$, from which:

$$
\begin{aligned}
\mathscr{G}_{f} & =\frac{1}{2}\left(\frac{1}{E}-\frac{1}{E_{\mathrm{t}}}\right) f_{\mathrm{t}}^{\prime 2} w_{c} \\
& =\frac{1}{2}\left[f_{\mathrm{t}}^{\prime} \varepsilon_{p}+f_{\mathrm{t}}^{\prime}\left(\varepsilon_{0}-\varepsilon_{p}\right)\right] w_{c}=W w_{c},
\end{aligned}
$$

where $W=\int \sigma_{z} d \varepsilon_{z}$. This conclusion, however, holds 
only if no plastic deformations accompany tensile microcracking, as we tacitly assumed ( $c f$. Ref. [3]).

Conversely, by measuring $\mathscr{G}_{f}, f_{t}^{\prime}$ and $E_{r}$, it is possible to determine the width of the fracture process zone, namely:

$w_{c}=\frac{2 \mathscr{G}_{f}}{f_{t}^{\prime 2}}\left(\frac{1}{E}-\frac{1}{E_{t}}\right)^{-1}$.

This is, of course, just an effective width corresponding to the assumed piece-wise linear stress-strain diagram and to the assumption of uniform strain within the fracture process zone, implied in Equation 5. The actual width of crack band front can be quite different, depending on the definition of the smallest microcrack size to be included in the crack band.

\section{EFFECT OF TRIAXIAL STRESS STATE}

By linking fracture to stress-strain relations, we can easily take into account the effect of triaxial stress state in the fracture process zone. As is well known from the tests of the biaxial failure envelope $[31,32]$, application of transverse compressive stress $\sigma_{x}$ or $\sigma_{y}$ (or both) reduces the tensile strength limit for $\sigma_{z}$ from $f_{t}^{\prime}$ to some value $f_{t c}^{\prime}$. On the other hand, positive $\sigma_{x}$ (or $\sigma_{y}$ ) seems to cause no increase in the strength limit for $\sigma_{z}$. These facts may be characterized by setting:

$$
\begin{gathered}
\text { for } \quad \Delta f_{t}^{\prime} \leqslant 0: \quad f_{i c}^{\prime}=f_{i}^{\prime}+\Delta f_{i}^{\prime} ; \\
\text { for } \quad \Delta f_{t}^{\prime}>0: \quad f_{i c}^{\prime}=f_{i}^{\prime} \\
\text { with } \quad \Delta f_{t}^{\prime}=k\left(\sigma_{x}+\sigma_{y}\right) ;
\end{gathered}
$$

in which $k$ is a positive constant. Since the biaxial failure envelope may be approximately considered as a straight line connecting the points for the uniaxial compression failure and the uniaxial tension failure, we may use the approximation:

$k=f_{i}^{\prime} / f_{c}^{\prime}$,

where $f_{c}^{\prime}=$ compression strength (taken as a positive number). In Equation 17 we use $\left(\sigma_{x}+\sigma_{y}\right)$ because this is an invariant for coordinate rotations about axis $z$, which should have no effect on the strength limit. We do not need however the invariants for arbitrary coordinate rotations because axis $z$ is fixed by the orientation of microcracks.

The use of stress-strain relations would also permit introducing easily the effects of loading rate and duration of sustained load upon fracture. This is however beyond the scope of this work.

\section{COMPUTATIONAL ASPECTS AND OBJECTIVITY OF MODEL}

In an incremental step-by-step solution of a problem that does not involve any unloading of the material, the following criteria may be observed with regard to the fracture modeling:

(1) When in a certain element the maximum principal strain $\varepsilon_{I}$ in the previous loading step equals or exceeds $\varepsilon_{p}$, we switch to using for the tangential compliance matrix of this element the matrix from Equation 3; we also orient the axes $x$ and $z$ in the directions of the principal strains in that step and keep them at fixed orientation with regard to the material for all subsequent loading steps while strain-softening takes place. [The fact that we keep these directions fixed even if shear stresses are subsequently produced on the plane $(x, y)$ is of course a simplification.]

(2) When $\varepsilon_{z}$ in the previous step equals or exceeds $\varepsilon_{0}$ we switch to the compliance (or stiffness) matrix for completely cracked material.

It might at first seem that the last criterion misses the effect of $\sigma_{x}$ and $\sigma_{y}$; however, it does not, since for very small $\mu$ Equation 6 yields an almost unique relationship between $\sigma_{z}$ and $\varepsilon_{z}$, the effect of $\sigma_{x}$ and $\sigma_{y}$ on $\varepsilon_{z}$ becoming negligible as $\mu \rightarrow 0$.

As for the mesh selection, a uniform square mesh seems most appropriate since it preserves during propagation the width of the crack band. If the crack path is unknown in advance, meshes other than a square mesh are unsuitable because they would introduce bias, favoring some crack paths over others.

In the general case of a fracture that is not parallel to the mesh lines, the crack band has a zig-zag shape ( fig. $4 e$ ). We must however keep in mind that this is just a numerical model for a smooth crack band, and we must therefore decide the value $w_{c}$ of the width of a smooth band which corresponds to our zig-zag band. Restricting attention to square meshes, it seems most reasonable [6] to assume that $w_{c}=A / \Delta a$ where $A=h^{2}=$ element area, $\Delta a=h \cos \alpha=$ length of smooth crack band advance when the zig-zag band advances by one element, and $\alpha=$ angle of the mesh line along which the crack band advances with the crack direction. Thus, $w_{c}=h^{2} / h \cos \alpha$ or:

$w_{c}=\frac{h}{\cos \alpha}$.

It appears, however, that this relation must be limited to $|\alpha| \leqslant 45^{\circ}[4 a, 4 b]$.

An essential aspect of numerical modeling is objectivity, in particular the requirement that the results must be independent of our mesh choice (except for a numerical error which tends to zero). In previous works on linear fracture analysis $[5,6,16]$ it was shown that objectivity can be achieved only if the strength limit is not kept fixed but is made to depend on the element size, so as to ensure the correct energy release rate. In our nonlinear model, we have, in addition to fracture energy, one more material parameter-namely the strength limit $f_{t}^{\prime}$ (or the strain-softening mociulus $E_{t}$ ). How do we assure objectivity of the results with regard to these parameters? 
The strain $\varepsilon_{z}$ within the fracture process zone does not seem to be a very important quantity. A true continuum which exhibits strain-softening is, after all, unstable. The main significance of $\varepsilon_{z}$ is that it defines the overall relative displacement $\varepsilon_{z} w_{c}$ over the width $w_{c}$; this in turn determines the work of the surrounding structure on the fracture process zone, which is the main part of the fracture energy. Thus, it should not matter when an element-wide crack band of width $h$ (the size of square) is considered instead of the actual width $w_{c}$ of the fracture process zone, provided that the correct value of the fracture energy is preserved. So, we may adjust the softening modulus $E_{t}$ as long as $\mathscr{G}_{f}$ remains the same. Replacing $w_{c}$ by $h$ in Equations 14 15 , we see that the following adjustments are needed when $h$ is chosen larger than $w_{c}$ :

$C_{f}=\frac{f_{t}^{\prime 2} h}{2 \mathscr{G}_{f}}, \quad \varepsilon_{0}=\frac{2 \mathscr{G}_{f}}{f_{i}^{\prime} h}$,

$E_{\mathrm{t}}=\left(\frac{1}{E}-\frac{2 \mathscr{G}_{f}}{f_{\mathrm{t}}^{\prime 2} h}\right)^{-1}$.

Since the tangent strain-softening modulus $E_{\mathrm{t}}$ must be negative, Equation 4 yields the condition $E_{\mathrm{t}}^{-1}=E^{-1}-C_{f}^{-1}<0$. It follows that $C_{f}<E$, and since also $E_{t}^{-1}=E^{-1}-2 G_{f} / f_{t}^{\prime 2} h<0$, the adjustments in Equation 20 can be used only if:

$h<\frac{2 \mathscr{G}_{f} E}{f_{i}^{\prime 2}}$,

In practice, the finite element should be less than about $1 / 2$ of this value. The limiting case $h=2 \mathscr{G}_{f} E / f_{t}^{\prime 2}$ corresponds to $E_{t}^{-1}=0$ or $E_{t} \rightarrow-\infty$, which amounts to a sudden (vertical) stress drop ( fig. 4d).

Note that, except for the factor 2, the expression in Equation 21 is of the same form as Irwin's expression for the size of the yielding zone in ductile fracture [30]. An expression similar to Irwin's was also used as a characteristic length in Hillerborg-Petersson's model [20].

To verify that our model is objective, in the sense that the results are independent of the chosen element size, an example of a rectangular center-cracked panel was analyzed; see figure 5 . It is the same example as that used before in demonstrating objectivity for the linear fracture analysis [6]. The top and the bottom of the panel are loaded at their centers by force $P$. We consider three meshes with mesh sizes $h=4 w_{c}, h=2 w_{c}$ and $h=w_{c}$. For the first two meshes, we adjust $E_{t}$ according to Equation 20.

Four-node square elements consisting of four constant strain triangles are used; $E=3,000,000 \mathrm{lb}$./in. ${ }^{2}, v=0.18$, $\mathscr{G}_{f}=0.12 \mathrm{lb}$./in., $f_{t}^{\prime}=330 \mathrm{lb}$./in. ${ }^{2}$; also $b=10 \mathrm{in}$., $H=10$ in., $B=1$ in. For each crack band length a, and for each mesh, we run a step-by-step loading analysis, controlling increments of the displacements at the centers of the top and bottom sides. Thus, we determine the maximum reaction $P$ of the panel. This reaction (load) is indicated in figure $5 d$ in terms of the load ratio $P / P_{0}$ in which $P_{0}$ is defined as $2 b f^{\prime}$, i. e., the maximum load based on the strength at no crack.

We see in figure $5 d$ that the results for all three meshes fall into a relatively narrow band. Moreover, the results are quite close to the exact solution according to linear fracture mechanics $[22,48]$, which is marked by the solid line in figure $5 d$.

For comparison we also show in figure $5 d$ by dashed lines the results obtained when the adjustments in Equation 20 are ignored, i. e. $E_{t}$ is kept constant. We see large discrepancies between the results (as $h \rightarrow 0$, the maximum load $P$ converges, incorrectly, to zero). Such calculations are obviously unobjective. The discrepancies are however not as large as they are for a vertical stress drop and a constant strength criterion [5-7, 16]. (One could also show that similar discrepancies between the results for the three meshes in figure $5 b$ would result if some of the existing continuous damage mechanics formulations, which do not include an energy criterion and $a$ characteristic length, were used.)

For large structures, e. g. when the cross section size is 100 or 1000 times the aggregate size, the element size limit in Equation 21 would be prohibitively small. This limit can, however, be violated if we consider a vertical stress drop ( fig. $4 d$ ) and replace the actual strength $f_{c}^{\prime}$ with a smaller equivalent strength $f_{\mathrm{eq}}$ such that the correct fracture energy be preserved, i.e. such that $h\left(f_{\mathrm{eq}}^{2} / 2 E\right)=\mathscr{G}_{f}$. This yields the condition:

$f_{\mathrm{eq}}=\left(2 E G_{j} / w_{c}\right)^{1 / 2}$,

which coincides with the equivalent strength derived earlier [5-7, 16] (in a different manner). For not too crude meshes, the use of a vertical stress drop yields results essentially the same as linear fracture mechanics $[5-7,16]$. Thus, linear fracture mechanics is the limiting case of the present formulation, applicable when the structure is very large compared to $w_{c}$, or to the maximum aggregate size ( fig. $1 a$ ).

\section{ANALYSIS OF EXPERIMENTAL DATA}

Most of the important test data from the literature $[13-15,17,19-21,25,26,38,39,44,45,47,49,50]$ have been successfully fitted with the present model. See the solid lines in figures 6-11. The best possible fits by linear fracture mechanics are also shown in these figures (dashed lines). The data used include various specimen geometries, sizes and loading conditions. The material parameters corresponding to the fits are listed in Table I. The fits were calculated using rectangular finite elements consisting of four constant strain triangles. A plane stress state was assumed for all calculations.

Initially, each data set was fitted independently, considering not only $\mathscr{G}_{f}, f_{t}^{\prime}$ but also $w_{c}$ as independent material parameters that can differ from concrete to concrete. For the optimum fits thus obtained, the ratio 

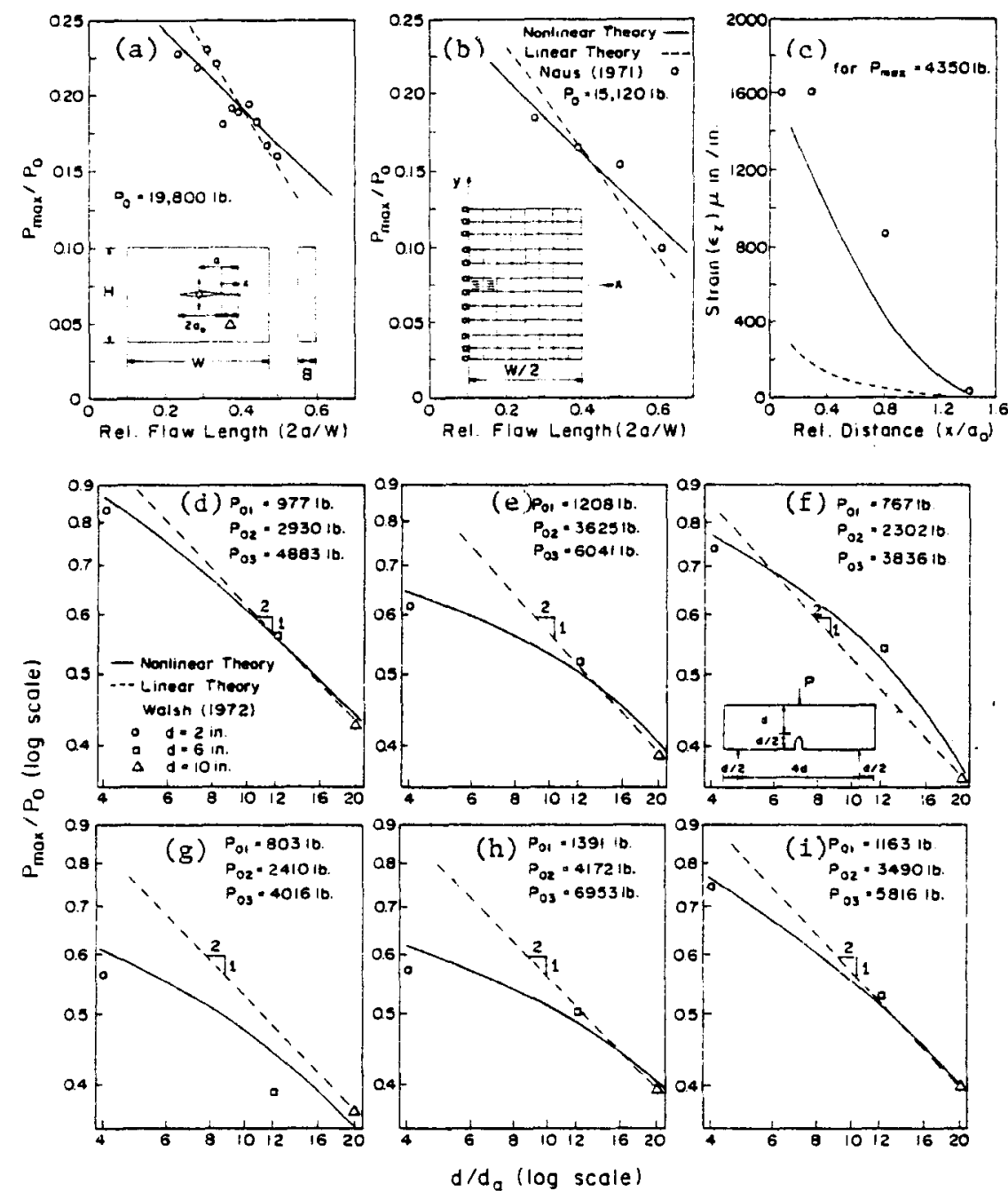

Fig 6. - Comparison of theory with maximum load data of Naus (1971); (a) Test series LC-1-AD-C; (b) Test series QC-1-SLW-C; (c) Strain distribution; and comparison of theory with Walsh's (1972) Data on notched beams of various sizes: $(d)$ Walsh's Series $\mathrm{t} ;(e)$ Series $2 ;(f)$ Series 3; $(g)$ Series 4; $(h)$ Series 5; (i) Series 6.
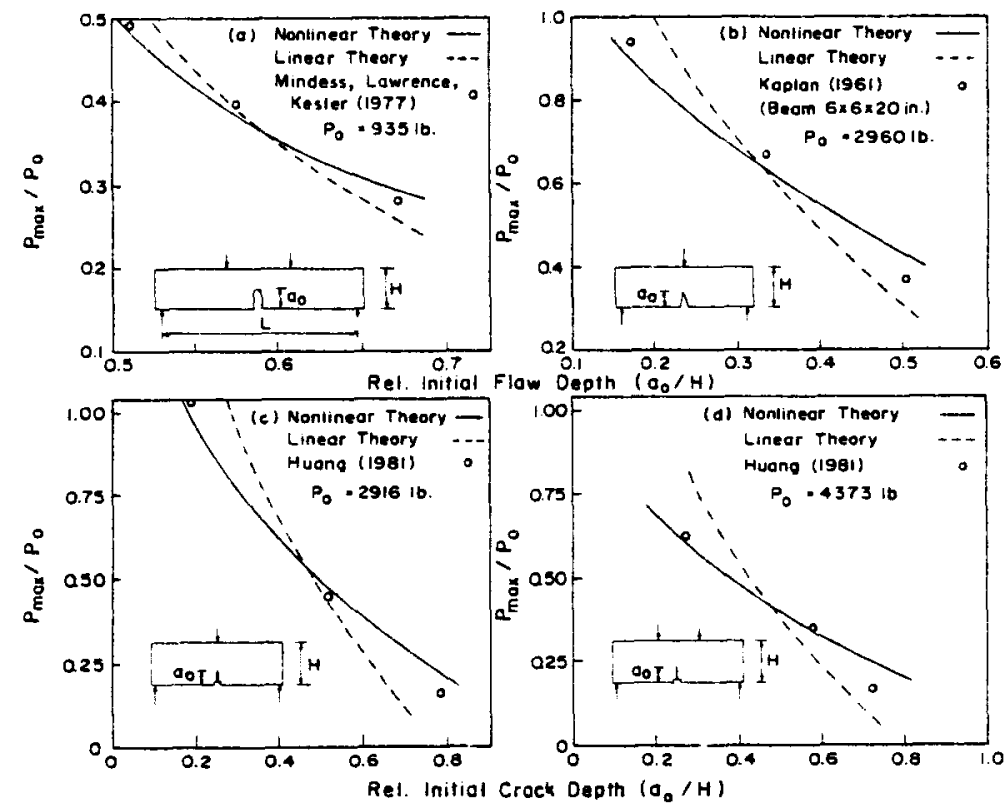

Fig. 7. - Comparison of theory with meximum load data of: (a) Mindess, Lawrence and Kesier (1977); (b) Kaplan (1961); (c, d) Huang (1981). 
Vol. $16-\mathrm{N}^{\bullet} 93$ - Matériaux et Constructions
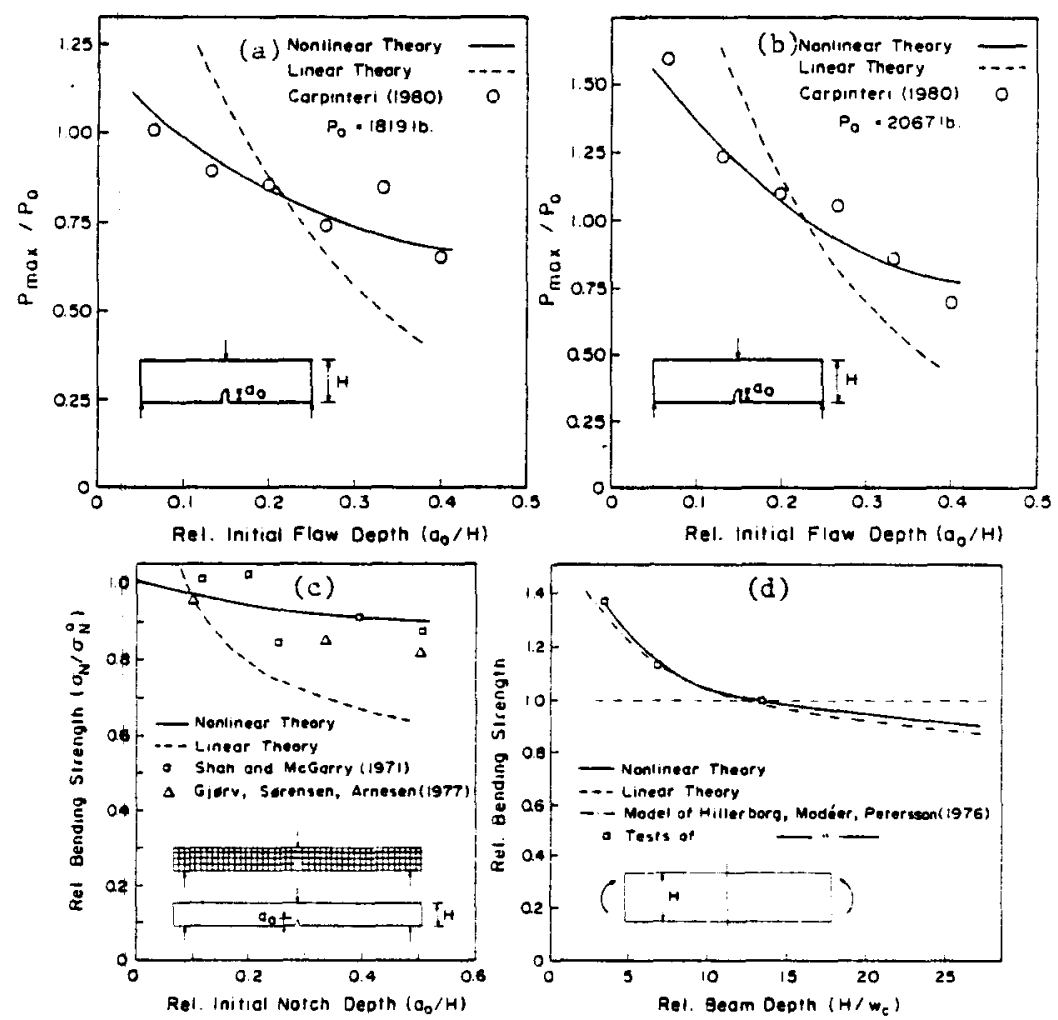

Fig. 8. - Comparison of theory with thaximum load data of $(a, b)$ Carpinteri (1980), comparison of theory with bending strength data of: (c) Shah and McGarry (1971), and Gjorv, Sorensen and Amesen (1977); (d) Hillerborg. Modéer and Petersson (1976).

of $w_{c}$ to the size of aggregate $d_{a}$ ranged from 1.5 to 4 for various concretes. Subsequently, the optimum fits were sought under the restriction that the ratio $w_{c} / d_{a}$ be the same for all concretes and only $\mathscr{G}_{f}$ and $f_{i}^{\prime}$ vary from concrete to concrete (table). The resulting value of $w_{c} / d_{a}$ was about 3.0 , and it was found that by restricting $w_{c} / d_{a}$ to be constant, the coefficient of variation for the deviations of the data points from the fits increased only slightly. Therefore, it is generally possible to assume that:

$$
w_{c} \simeq 3 d_{a},
$$
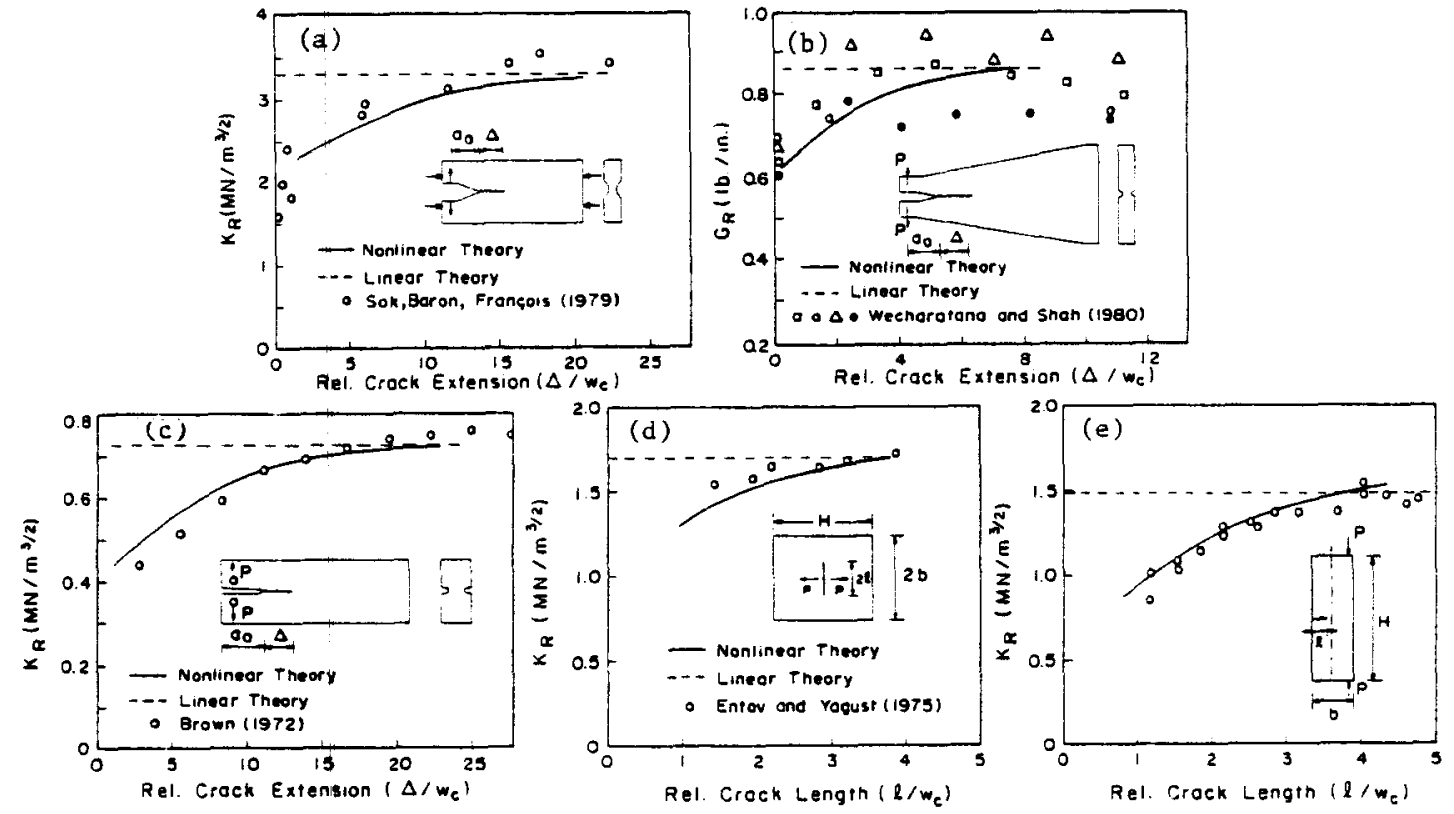

Fig. 9. - Comparison of theory with R-curve data of: (a) Sok, Baron and François (1979);

(b) Wecharatana and Shah (1980); (c) Brown (1972); (d, e) Entov and Yagust (1975). 
The foregoing result refers to an effective $w_{c}$-value obtained under the assumption of uniform strain over the width $w_{c}$, implying a uniform distribution of microcracks. The actual width of the microcracked zone, in which the density of microcracks varies across the zone (being the highest in the center), would no doubt be somewhat different.

The width $w_{c} \simeq 3 d_{a}$ is about the minimum admissible from the viewpoint of continuum smoothing of the
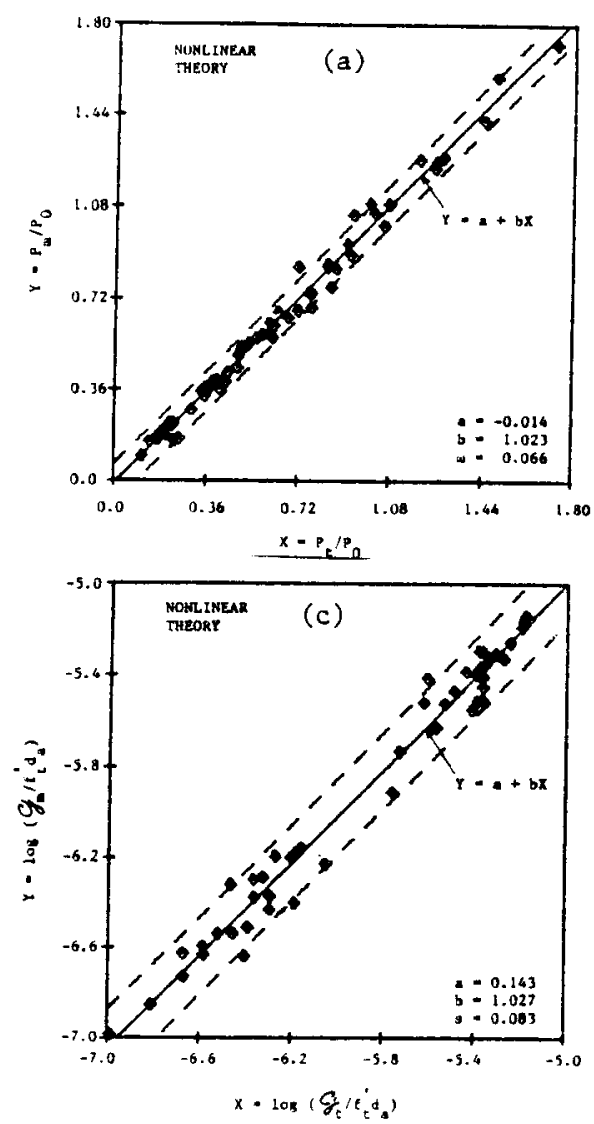

randomly inhomogeneous material, i. e., about the minimum acceptable as the dimension of the representative volume (e.g., $w_{c}=d_{a}$ would not justify treating the crack band as a homogeneously strained region). However, from the viewpoint of data fitting, the results for, say, $w_{c}=1.5 d_{a}$, would not be much worse, provided the same value of fracture energy $\mathscr{G}_{f}$ would be preserved. To preserve it, however, the downward slope $E_{\mathrm{t}}$ of the strain-softening segment would have to be
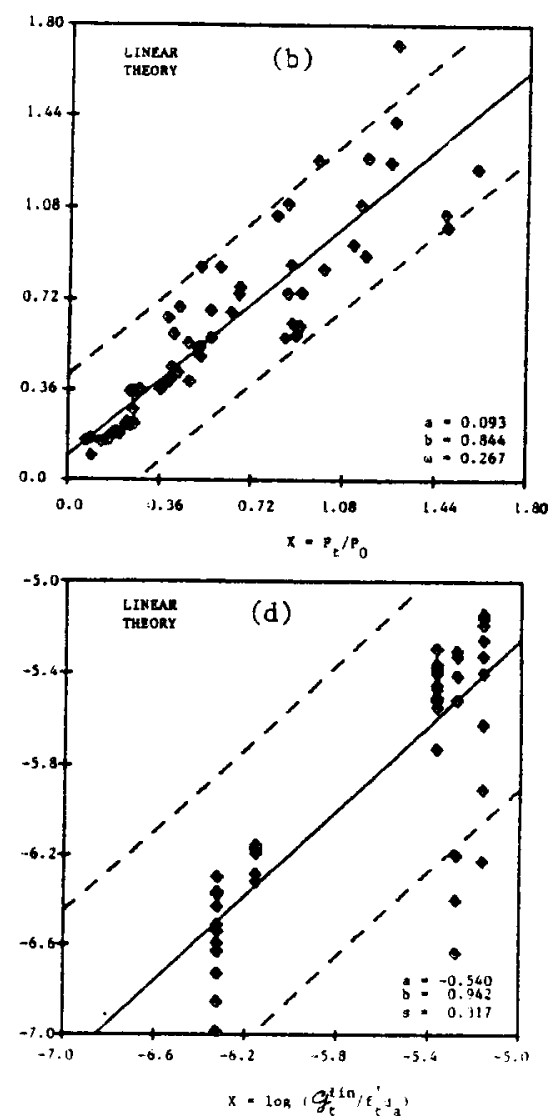

Fig. 10. $-(a, b)$ Plots of measured versus theoretical values of maximum loads from figures $6-8 ;(c, d)$ Plots of measured versus theoretical values of energy release rate from figure 9.
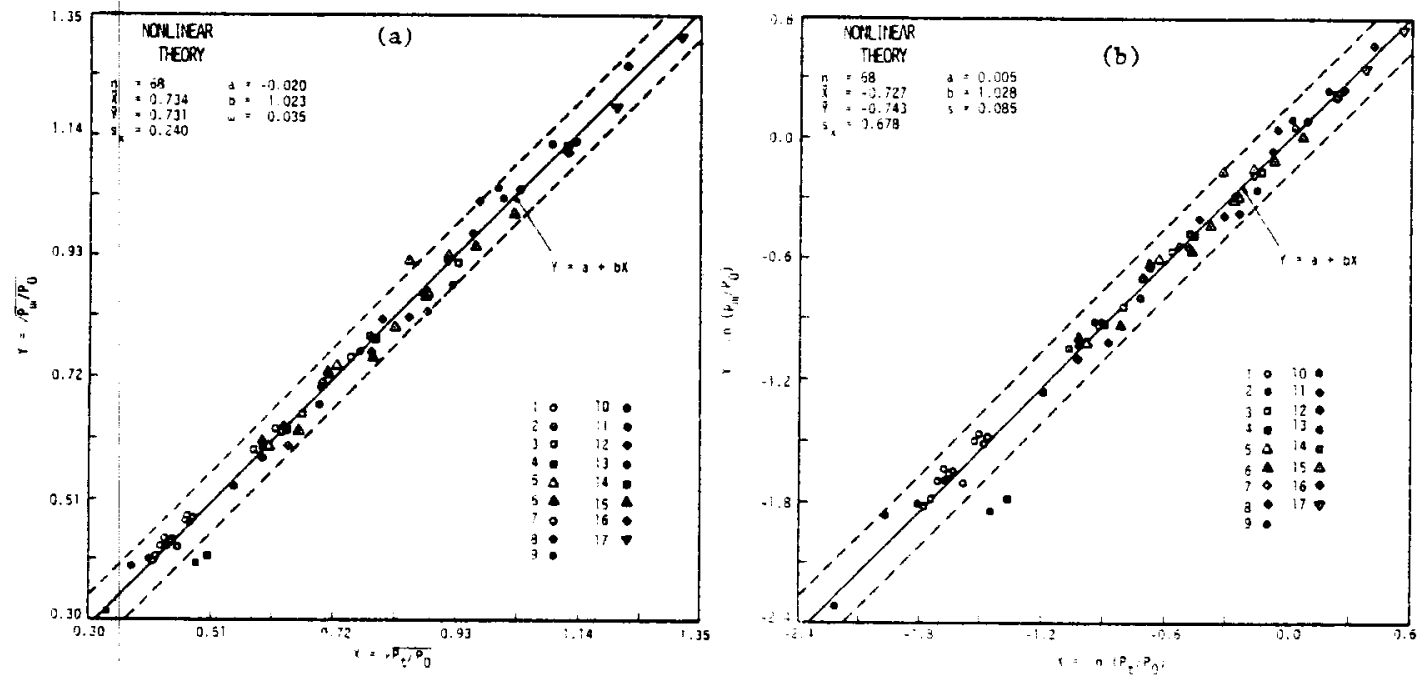

Fig. 11. - Plots of measured versus theoretical values of maximum loads from figures 6-8 (same as Figure $10 a, b$ but different scales). 
unreasonably small in comparison with measurements such as the direct tensile tests of Evans and Marathe [18]. If their specimens were indeed homogeneously deformed on the macroscale (i. e., disregarding concentrations and scatter within distances less than $3 d_{a}$ ), then the value $w_{c} \simeq 3 d_{a}$ is a physical reality; if not, then this value may be adjusted.

The constancy of $w_{c} / d_{a}$ is doubtless applicable only as an approximation. We may expect the ratio $w_{c} / d_{a}$ to be a function of concrete strength. When the difference between the elastic moduli of the large aggregate pieces and of the mortar between them becomes less, as e. $g$. for high strength concrete, the material becomes more homogeneous, and so $w_{c} / d_{a}$ should decrease. The opposite should happen when a concrete of very low strength is considered, or when the aggregate-cement bond becomes weaker, reinforcing bars or fibers are used, etc.

In figures 6-9 we show by the solid curves the fits of maximum load data obtained with our nonlinear theory. For comparison, we also show in all figures by the dashed lines the best fits based on linear fracture mechanics. These fits were calculated with the blunt smeared crack band approach on the basis of the energy flow into the front element (Equations 12-13 of Ref. [5] or Equations 8-10 of Ref. [7]), and with the assumption of a sudden stress drop. This method of calculation was previously shown to yield results that deviate from the exact fracture mechanics solutions by no more than about $2 \%$, provided the mesh is not too coarse.

Figure $6 a, b$ shows a comparison of our theory with the well-known tests by Naus, Kesler and Lott [26, 39], indicating a decrease of the maximum load $\boldsymbol{P}_{\max }$ as the initial flaw length $a_{0}$ increases. (In fig. $6 a, b$, $P_{0}=W B f_{\ell}^{\prime}$ where $W=$ width of specimen, $B=$ its thickness, $\Delta=$ crack advance, and $f_{t}^{\prime}=$ tensile strength; see Table I). Also shown are the best fits by a linear theory (dashed lines). It is rather interesting to note that, for the maximum load the fits for the linear theory are also acceptable and not much worse than those for our nonlinear theory. This observation agrees with a recent perspicacious reinterpretation of Naus' tests by Ingraffea [43]. He found that when a certain recently published more accurate analytical solution or an accurate finite element solution is used, then Naus' maximum load data, originally thought to disprove linear fracture mechanics, do not show large deviations.

May we, therefore, conclude that tests of Naus, Kesler and Lott $[26,39]$ confirm linear fracture mechanics? We may not. Naus fortunately also measured the strains $\varepsilon_{z}$ on axis $x$ ahead of the crack front. The linear theory strongly disagrees with these strain measurements while our nonlinear theory comes reasonably close. So, after all, the tests of Naus, Kesler and Lott do confirm the need for a nonlinear fracture theory (see fig. 6c)

The reason that the maximum load data for these tests can be reconciled with a linear theory probably is (as T. Ingraffea also mentioned to the writers) that the maximum load is, for this type of specimen, reached at a very small crack extension so that fracture energy values for all cases tested correspond to the beginning of the $R$-curve, characterized by a single value of fracture energy (a rather low value, as noted by others before).

The best test data on the size effect for geometrically similar specimens are perhaps those of Walsh [49], and the comparisons with them are shown in figure $6 d-i$. For this figure $P_{0}=3 B d f_{t}^{\prime} / 8=$ maximum load based on the bending theory for an uncracked beam, and $P_{01}=P_{0}$

TABLE I

PARAMETERS FOR TEST DATA

\begin{tabular}{|c|c|c|c|c|c|c|c|c|}
\hline Test Series & $\begin{array}{c}f_{t}^{\prime} \\
\text { (psi) }\end{array}$ & $\begin{array}{c}E_{c} \\
(\mathbf{k s i})\end{array}$ & $\begin{array}{c}\mathscr{S}_{f} \\
(l b . / \text { in. })\end{array}$ & $\begin{array}{c}d_{a} \\
\text { (in.) }\end{array}$ & $\begin{array}{c}w_{c} \\
\text { (in.) }\end{array}$ & $\begin{array}{c}3_{f}^{\text {tin }} \\
\text { (lb./in.) }\end{array}$ & $c_{S}$ & $\begin{array}{c}\tilde{\mathscr{G}}_{f} \\
\text { (lb./in.) }\end{array}$ \\
\hline 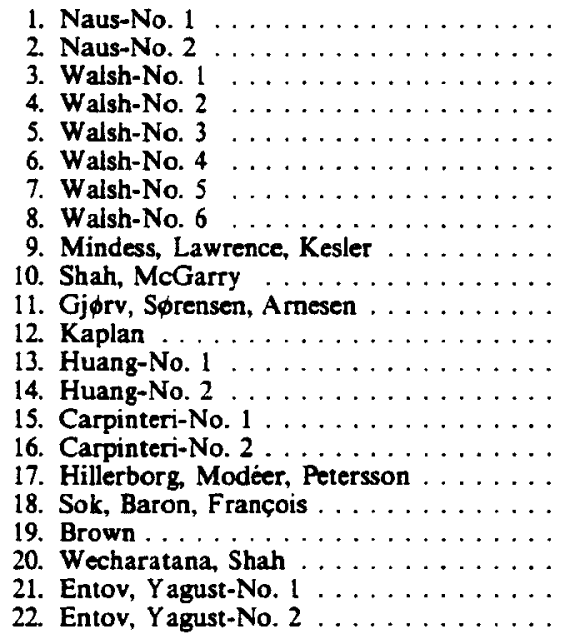 & $\begin{array}{l}460^{*} \\
360^{*} \\
347^{*} \\
430^{*} \\
273^{*} \\
286^{*} \\
495^{*} \\
414^{*} \\
370^{*} \\
300^{*} \\
300^{*} \\
300^{*} \\
360^{*} \\
360^{*} \\
313^{*} \\
356^{*} \\
400^{*} \\
740^{*} \\
690^{*} \\
740^{*} \\
450^{*} \\
440^{*}\end{array}$ & $\begin{array}{l}4,450^{*} \\
4,500^{*} \\
3,299^{*} \\
4,083^{*} \\
2,593^{*} \\
2,716^{*} \\
4,697^{*} \\
3,928 * \\
6,260 \\
3,000^{*} \\
3,000^{*} \\
4,190 \\
3,122 * \\
3,122 * \\
2,700 * \\
3,130^{*} \\
3,300^{*} \\
3,000^{*} \\
2,200^{*} \\
3,000^{*} \\
3,000^{*} \\
3,000^{*}\end{array}$ & $\begin{array}{l}0.205^{*} \\
0.099^{*} \\
0.174^{*} \\
0.188^{*} \\
0.126^{*} \\
0.133^{*} \\
0.224^{*} \\
0.193^{*} \\
0.088^{*} \\
0.108 * \\
0.108 * \\
0.101 \\
0.225^{*} \\
0.225^{*} \\
0.207^{*} \\
0.280^{*} \\
0.100^{*} \\
2800^{*} \\
0.182^{*} \\
0.855^{*} \\
0.746^{*} \\
0.640^{*}\end{array}$ & $\begin{array}{l}0.375 \\
0.375 \\
0.50 \\
0.50 \\
0.50 \\
0.50 \\
0.50 \\
0.50 \\
0.375 \\
0.375 \\
0.375 \\
0.50 \\
0.50 \\
0.50 \\
0.375 \\
0.752 \\
0.157 \\
0.472 \\
0.047 \\
0.250 \\
0.787 \\
0.787\end{array}$ & $\begin{array}{l}1.125^{*} \\
1.125^{*} \\
1.50^{*} \\
1.50^{*} \\
1.50^{*} \\
1.50^{*} \\
1.50^{*} \\
1.50^{*} \\
1.125^{*} \\
1.125^{*} \\
1.125^{*} \\
1.50^{*} \\
1.50^{*} \\
1.50^{*} \\
1.125^{*} \\
2.256^{*} \\
0.471^{*} \\
1.416^{*} \\
0.141^{*} \\
0.750^{*} \\
2.360^{*} \\
2.360^{*}\end{array}$ & $\begin{array}{l}0.430^{*} \\
0.249^{*} \\
0.188^{*} \\
0.173^{*} \\
0.158^{*} \\
0.162^{*} \\
0.173^{*} \\
0.176^{*} \\
0.170^{*} \\
0.047^{*} \\
0.047^{*} \\
0.177^{*} \\
0.337^{*} \\
0.245^{*} \\
0.147^{*} \\
0.201 * \\
0.118^{*} \\
2.910^{*} \\
0.185^{*} \\
0.860^{*} \\
0.755^{*} \\
0.630^{*}\end{array}$ & $\begin{array}{l}7.664^{*} \\
6.111^{*} \\
6.356^{*} \\
5.535^{*} \\
5.845^{*} \\
5.888^{*} \\
5.725^{*} \\
5.897^{*} \\
7.154^{*} \\
6.400^{*} \\
6.400^{*} \\
6.269^{*} \\
7.227^{*} \\
7.227^{*} \\
10.14^{*} \\
6.130^{*} \\
8.758^{*} \\
21.66^{*} \\
11.93^{*} \\
12.49^{*} \\
9.366^{*} \\
8.405^{*}\end{array}$ & $\begin{array}{l}0.224^{*} \\
0.113^{*} \\
0.185^{*} \\
0.270^{*} \\
0.123^{*} \\
0.133^{*} \\
0.348^{*} \\
0.253^{*} \\
0.087^{*} \\
0.103^{*} \\
0.103^{*} \\
0.098^{*} \\
0.217^{*} \\
0.217^{*} \\
0.128^{*} \\
0.315^{*} \\
0.086^{*} \\
1.600^{*} \\
0.178^{*} \\
0.848^{*} \\
0.657^{*} \\
0.617^{*}\end{array}$ \\
\hline
\end{tabular}

Note: psi $=6895 \mathrm{~N} / \mathrm{m}^{2}, /$ b. $/$ in. $=175.1 \mathrm{~N} / \mathrm{m}$, in. $=25.4 \mathrm{~mm} . \mathrm{ksi}=1000 \mathrm{psi}$.

- asterisk indicates numbers estimated by calculations; without asterisk-as reported. 
for $d=2$ in., $P_{02}$ for $d=6 \mathrm{in}$, and $P_{03}$ for $d=10 \mathrm{in}$. Here (and also in fig. $8 d$ ) the linear theory lines (dashed) were made to pass through the data point for the largest specimen of each series because linear fracture mechanics should apply on a sufficiently large scale. Note that the strength criterion would for these tests predict horizontal lines, obviously disagreeing with tests.

Figure $7 a$ shows a comparison with the data by Mindess, Lawrence and Kesler [38] on the dependence of the maximum load on the crack length in four-point bent specimens, and figure $7 b$ shows a comparison with similar classical tests of Kaplan [25], indicating a decrease of the maximum load of notched beams with the crack length. Figure $7 c, d$ shows a comparison with similar data for notched and precracked beams by Huang [21]. Figure $8 a, b$ also shows the comparisons with the maximum load data for notched beams by Carpinteri $[14,15]$. For these tests, $P_{0}$ is defined as the maximum load of uncracked beam based on the bending theory.

Figure $8 c$ shows a comparison with the data of Shah and McGarry [44] and of Gjфrv, Sorensen and Arnesen [19] on the maximum bending moment of three-point bent specimens as a function of the notch depth $a_{0} ; \sigma_{n}=6 M_{\text {max }} / B\left(H-a_{0}\right)^{2}=$ nominal maximum bending stress calculated on the basis of notched cross section using the initial notch length $a_{0}$ ( $H=$ beam depth, $B=$ beam width) $\sigma_{n}^{0}=6 M_{\mathrm{max}}^{0} / B H^{2}=$ nominal maximum bending stress of unnotched beam (i. e., for $\left.a_{0}=0\right) ; M_{\max }=P_{\max } L / 4=$ measured maximum bending moment for notched beam, $M_{\max }^{0}=P_{\max }^{0} L / 4=\operatorname{maximum}$ bending moment for $a_{0}=0, L=$ span of beam.

Figure $8 d$ shows a comparison with the data of Hillerborg, Modéer and Petersson [20], indicating how the bending strength of unnotched, initially uncracked, beams increases as the beam depth $H$ increases. According to linear fracture mechanics, this effect is nonexistent if no notch or flaw exists near the tensile face; therefore, a horizontal, dashed line, is drawn in figure $8 d$. The value of $\mathscr{G}_{f}^{\text {lin }}$ in table $I$ is in this case determined from the optimum fit of the maximum load data for the specimen of the largest depth. The relative bending strength is here defined as the ratio between the bending strength at the various beam depths and the bending strength at the largest beam depth.

Figure 9 shows comparisons with the recent data on the so-called $R$-curves (resistance curves) $[13,17,45$, 50], which represent the dependence of fracture energy on the crack length in slow stable crack growth. The test specimens of Sok, Baron and François ( $f i g .9 a$ ) were probably the largest specimens ever used (length up to $2.5 \mathrm{~m}$ ). These specimens were prestressed in the direction parallel to the crack, in order to prevent a curved crack path. The prestress was modeled as applied loads ( fig. $9 a$ ) and the tensile strength limit was reduced according to Equation 17. To simulate these tests, it was necessary to calculate in the finite element program the energy release rate $\mathscr{G}$ (from which the stress intensity factor $K$ follows as $\sqrt{E \mathscr{G}}$ ). This was done by approximating $\mathscr{G}$ at midstep as $\Delta W /(b \Delta a)$ where $\Delta W=\Sigma P_{i} \Delta u_{i}-\Delta U ; \quad b=$ thickness of plate, $P_{i}=$ values of the loads $(i=1,2, \ldots)$ at midstep, $\Delta a=$ crack length increment during the loading step. $\Delta u_{i}=$ increments of displacements under the loads, and $\Delta U=$ change from one load state to the next in the sum of the strain energies of all finite elements, both those inside and those outside the crack band. (Note that the contribution of loads and of the linearily behaving elements to $\Delta W$ may be more efficiently calculated as the work that the forces applied upon the boundary nodes of the nonlinear zone from the surrounding elements do on the displacements of these boundary nodes.) The transverse groove used by the experimentalists to stabilize the crack in the straight direction is taken into account. The horizontal dashed lines for the linear theory are made to fit the results for the longest cracks since these should agree with the linear theory.

In fitting the data by Entor and Yagust [17], the value of $E_{c}$ reported by them appeared too high. They did not indicate whether $E_{c}$ was measured at roughly the same strain rate as that during the fracture tests (the fracture specimens were different), whether possibly unloading or reloading was used, etc. Such differences could explain why the present fitting of their data required a lower value of $E_{c}$ than they reported (as given in table I). Furthermore, the $f_{t}^{\prime}$ values for Entov and Yagust's tests, as well as those for Naus' tests, were also adjusted (see table I) since they did not come from direct tension tests.

The values of $\mathscr{G}_{f}^{\text {in }}$ listed in Table I often markedly differ from $\mathscr{G}_{f}$ values. Different values were necessary to obtain least-square optimum fits of test data with the linear theory. If $\mathscr{G}_{j}^{\text {lin }}=\mathscr{G}_{f}$ were assumed, the deviations of the linear theory would have been much larger.

The curves in figures 6-9 all exhibit the type of size effect illustrated at the outset in figure $l a$. We may now explain this behavior. When the structure is small compared to the aggregate size, the fracture process zone cannot develop its full size, and almost the entire specimen belongs to it. Thus, there is no energy flux into the fracture process zone from the outside, and the energy consumption in this zone is small. Hence, nothing but surpassing the strength limit can cause failure. When the structure is very large compared to the aggregate size, the crack band is relatively very narrow and the fracture process zone is negligibly small, which satisfies the assumptions of linear fracture mechanics. The strength limit does not matter since it can always be exceeded, in view of the stress concentration at crack front, and so only fracture energy matters. The intermediate case should represent a gradual transition between these extremes, as shown in figure $1 a$.

It is instructive to extract from the finite element outputs the profiles of $\sigma_{z}$ along axis $x$. This is done in figure $4 f$ for the case of figure $9 c$ at one loading stage, and in figure $4 \mathrm{~g}$ for the case of figure $9 a$ at successive loading stages. The length of the fracture process zone. 
$l_{f}$, is the distance from the point where the $\sigma_{z}$-profile starts to rise to the point of maximum $\sigma_{-}$: see figure $4 f$. As the crack begins to grow, there is, at first, a nonzero stress at the notch surface $(\sigma=$ profiles $1,2,3,4$ in fig. $4 \mathrm{~g}$ ), and the strain is then less than the terminal strain $\varepsilon_{0}$ of strain-softening (point $C$ in fig. $4 \mathrm{~g}$ ). The fracture energy is the energy that cannot be recovered upon sudden unloading. Noting that the unloading slopes at the point on the notch surface for profiles 1 , $2,3,4$ are the lines PO, $3 \mathrm{~A}$ and $4 \mathrm{~B}$, we see that the fracture energy for the profiles $1,2,3,4$ of figure $4 \mathrm{~g}$ corresponds to incomplete areas under the stress-strain curve (zero areas for profiles 1,2 of fig. $4 \mathrm{~g}$, and areas OP3 A or OP4 B for profiles 3 or 4). When the $\sigma_{z^{-}}$ profile begins smoothly from a zero stress (profiles 5 , $6,7)$, the unrecoverable energy corresponds to the complete area under the stress-strain curve (area OPC). This is the case of a fully developed fracture process zone. The finite element results indicate for this case that $l_{f}$ is generally between $2 w_{c}$ and $6 w_{c}$, and the typical value is:

$l_{f} \simeq 4 w_{\mathrm{c}} \simeq 12 d_{a}$.

This result agrees with the observed $R$-curves. We may expect that the crack extension $\Delta a$ required to reach a constant value of $\mathscr{G}_{f}$ must be at least about 1 to $3 l_{f}$, and indeed figure 9 indicates such $\Delta a$ to be about 4 to $12 w_{c}$. Note also that the fracture process zone is much more elongated than the yielding zone in metal fracture; see figure $1 c, d$.

It is helpful to also explain how the model works for the $R$-curves. At the beginning of crack extension from a notch, the fracture process zone is not yet developed to its full length and width, and so the energy consumption in the fracture process zone is less than the fracture energy, while the crack extends due to surpassing the strength limit. For a long crack extension, the fracture process zone develops fully in size, and the energy consumption in it can reach the critical value. This explains that the apparent fracture energy should depend on the crack extension, increasing at the beginning and then stabilizing at its critical value. This dependence is called the resistance curve ( $R$-curve). Numerical examples in the sequel confirm this explanation.

The success in determining the $R$-curves from the stress-strain relation makes it unnecessary to consider the $R$-curve as the basic material property. It is well known that the $R$-curve can be a material property only in the asymptotic sense - when the crack extension from a notch is short enough. For metals this condition may often be met, but not quite for concrete, due to large fracture process zone. Hene the $R$-curves exhibit a significant variation over a distance that is not very small compared to the cross section dimension, and then the $R$-curve cannot be a material property, independent of the crack direction, crack path, and specimen geometry.

It must be noted that the foregoing analyses of all test data have been carried out under the assumption that the displacement at the loading points is controlled. This is assured if the loading frame is sufficiently stiff compared to the stiffness of the specimen, so as to prevent an instability which involves a sudden displacement at the loading point and allows a release of strain energy from the frame into the specimen. Anyhow, analysis of such instabilities is impossible since the experimentalists did not report the stiffness of the loading frame.

\section{STATISTICAL ANALYSIS OF ERRORS}

To determine statistical characteristics of errors, we construct in figure $10 a, b$ the plot of $Y=P_{m} / P_{0}$ versus $X=P_{d} / P_{0}$ where $P_{m}=$ measured $P_{\max }, P_{t}=$ theoretical $P_{\max }, P_{0}=$ failure load based on strength as defined before for each figure (in case of the data from fig. $8 c$, we use $\sigma_{n} / \sigma_{n}^{0}$ instead of $P_{\max } / P_{0}$ ). This plot, based on $M=68$ data points taken from figures $6-8$, is shown in figure $10 \mathrm{a}$. For comparison, we also show the same plot for the linear theory ( fig. $10 b$ ). In these plots, the points at top right correspond to relatively small specimens, which are governed essentially by the strength criterion, and those at bottom left correspond to relatively large specimens, which are governed essentially by fracture energy.

If the material behaved deterministically, and if our theory were perfect, the plot in figure $10 a$ would have to be a straight line $Y=a+b X$ with $a=0, b=1$. So, a linear regression analysis may be applied to this plot. The difference of $a$ from 0 and of $b$ from 1 then indicates possible improvement in the optimum calibration of our theory [which is seen to be negligible for figure $10 a$ ]. The errors, i. e., the vertical deviations of data points $Y_{i}$ from the regression line $Y^{\prime}=a+b X$, indicate how good the theory is. The coefficient of variation of the errors, defined as $\omega=s / \bar{Y}$ where $s=$ standard error, $s^{2}=\Sigma\left(Y_{i}-Y^{\prime}\right)^{2} /(n-2), \vec{Y}=\Sigma Y_{i} / n$, $i=1,2, \ldots, n \quad(s=0.039$ for nonlinear theory and $s=0.159$ for linear theory), is found to be:

for our fracture theory ( 2 fig. $10 \mathrm{a}$ ):

$$
\omega_{P}=0.066 \text {, }
$$

for linear fracture theory ( fig. $10 \mathrm{~b}$ ):

$$
\omega_{P}=0.267 \text {, }
$$

for strength criterion:

$$
\omega_{P}=0.650 \text {, }
$$

The above value for the strength criterion follows as the standard deviation of $Y_{i}$ divided by mean of $Y_{i}$ (since the strength criterion predicts constant $\left.P / P_{0}\right)$.

Figure $10 a, b$ has the disadvantage that too many data points crowd at low $P / P_{0}$ values. To remedy it, one may plot $Y=\left(P_{m} / P_{0}\right)^{1 / 2}$ versus $X=\left(P_{t} / P_{0}\right)^{1 / 2}$. The coefficient of variation of errors in this type of regression is $\omega=0.035$ for our theory (fig. 11 a), compared to $\omega=0.120$ for the linear fracture theory. Both this plot and the plot in figure $10 a$ have further the disadvantage that the confidence limits based on $\omega$ 
are, for very small $P / P_{0}$, too large compared to $P$; e. g. a deviation of $0.05 P_{0}$ in the value of $P$ is small when $P=0.9 P_{0}$ but large when $P=0.05 P_{0}$. This may be remedied by plotting $\ln \left(P_{m} / P_{0}\right)$ versus $\ln \left(P_{t} / P_{0}\right)$, for which the standard deviation of errors (relative to the regression line) is $\omega=0.085$ for our theory ( fig. $11 \mathrm{~b}$ ) and $\omega=0.220$ for the linear fracture theory. Note also that the $95 \%$ confidence limits in figure $11 b$ are much closer, relative to the magnitude of $P$, than those in figure $10 a$ when $P / P_{0}$ is small, while the opposite is true when $P / P_{0}$ is not small.

Another useful statistical measure is the coefficient of variation of the population of all $P_{m} / P_{t}$ values; it is found to be:

for our fracture theory:

$$
\omega_{m t}=0.080 \text {, }
$$

for linear fracture theory:

$$
\omega_{m t}=0.268 \text {. }
$$

We must remember that $P_{t}$ itself is random, depending on the random values of $f_{t}^{\prime}$ and $\mathscr{G}_{f}$.

The errors in figure $10 c, d$ for the $R$-curves may be analyzed similarly. To this end, it is appropriate to normalize the fracture energy with regard to the internal force transmitted by the fracture process zone, which is roughly proportional to $f_{t}^{\prime} d_{a}, d_{a}$ being the size of aggregate. Thus, we plot in figure $10 c, d$ the values of $\ln \left(\mathscr{G}_{s} / f_{t}^{\prime} d_{a}\right)$ from figure 9 using the measured value $\mathscr{G}_{m}$ of $\mathscr{G}_{f}$ on the $Y$-axis, and the theoretical value $\mathscr{G}_{t}$ of $\mathscr{G}_{f}$ on the $X$-axis. Again, if everything were perfect, this plot would have to be a straight line $Y=a+b X$, with $a=0, b=1$, and so a linear regression is applicable. The standard error for the vertical deviations from the regression line has been calculated to be:

for our fracture theory ( $f i g .10 \mathrm{c}$ ):

$$
s=0.083 \text {, }
$$

for linear fracture theory ( fig. $10 d$ ):

$$
s=0.317
$$

(Note that it would not make much sense to calculate the coefficient of variation for figure $10 c, d$ because the logarithmic scales used in this figure already characterize relative values.)

The $95 \%$ confidence limits corresponding to $\omega_{P}$ or $s$ from Equations 24 and 26 are plotted as the dashed curves in figures 10 and 11 . These curves are hyperbolas, but due to the large size of our statistical samples they are almost straight, and so the $95 \%$ confidence limits relative to mean $\vec{Y}$ are approximately $1.96 \omega_{P}$ or $1.96 \mathrm{~s}$.

We see from figures 10 and 11 , as well as Equations 24 and 26, that our theory brings about a significant improvement. Note however that this is strictly an improvement in predicting the relative changes $P_{i} P_{0}$ of failure load $P$ due to the size effects (size of structure, of crack, of initial notch, etc.). The value of $P_{0}$ is of course random, too, due to the well-known random variation of the tensile strength.
The coefficient of variation of $P_{0}$ may be considered to be roughly the same as the coefficient of variation $\omega_{t}$ of the tensile strength $f_{i}^{\prime \prime}$. Assuming that the random errors of $P / P_{0}$ and of $P_{0}$ are uncorrelated, and noting that the coefficient of variation $\omega_{P}$ of deviations $\Delta P$ from the regression line is the coefficient of variation of the product $\left(1 P P_{0}\right) P_{0}$, we may get :

$$
\begin{aligned}
\omega_{p} & \simeq\left(\omega_{t}^{2}+0.066^{2}+0.066^{2} \omega_{t}^{2}\right)^{1.2} \\
& =\left(1.004 \omega_{t}^{2}+0.066^{2}\right)^{1 / 2} .
\end{aligned}
$$

The standard error of $P$ then is $s_{P} \simeq P_{0} \omega_{P}$. This would represent, however, unreasonably large an error when $P / P_{0}$ is small. For such cases, it is preferable to set up a similar statistical estimate on the basis of the standard deviation $s_{P}^{\prime}$ of errors in the plot of $\ln \left(P / P_{t}\right)(f i g .11 b)$. The standard deviation of the deviations from $P / P_{t}$ is then roughly also $s_{P}^{\prime}$, and since $P_{t}$ itself is randomly scattered, being proportional to $\sqrt{\mathscr{G}_{f}}$, one must again properly combine $s_{P}$ with the coefficient of variation of $\mathscr{G}_{f}$ to get the coefficient of variation of $P$.

\section{PREDICTION OF FRACTURE ENERGY AND SOFTENING MODULUS}

The 22 data sets collected in table I allow us to verify a simple prediction formula for $\mathscr{G}_{f}$. Denoting the predicted value of $\mathscr{G}_{f}$ as $\tilde{\mathscr{G}}_{f}$, we get from Equation 16 $\widetilde{G}_{f}=1.5 c_{f} d_{a} f_{t}^{\prime 2} / E$ where $c_{f}=1-E / E_{t}\left(E_{t}<0\right)$. Now, calculating from Equation 16 the values of $E_{t}$ from the values of $\mathscr{G}_{f}, f_{t}^{\prime}, E$ and $d_{a}\left(E=E_{c}, w_{c}=3 d_{a}\right)$, as listed in table I, we obtain for coefficient $c_{f}$ the values listed in table I. They are not the same for various data, which is partly due to inevitable statistical scatter. A least-square regression analysis shows, however, that the values of $c_{f}$ in table I may be approximated by the simple formula $c_{f}=1.811+0.0143 f_{t}^{\prime}$. This yields:

$$
\begin{aligned}
& \mathscr{G}_{f} \simeq\left(2.72+0.0214 f_{t}^{\prime}\right) f_{t}^{\prime 2} \frac{d_{a}}{E} ; \\
& E_{t} \simeq \frac{-69.9 E}{56.7+f_{t}^{\prime}},
\end{aligned}
$$

in which $f_{t}^{\prime}$ must be in psi ( $\mathrm{psi}=6895 \mathrm{~Pa}$ ).

For all 22 data sets listed in table $I$, the errors of Equation 27 , i. e., $\mathscr{G}_{f}-\mathscr{G}_{f}$ (with $\overline{\mathscr{G}}_{f}$ and $\mathscr{G}_{f}$ listed in table. have the coefficient of variation:

$\tilde{\omega}_{f}=0.162$.

which seems acceptable. This is however only the error relative to the theoretical value $\mathscr{G}_{f}$, which itself has a statistical error. What is then the total coefficient of variation $\omega_{P}$ of experimental failure loads compared to predictions of our theory based on Equation 27? We may estimate it by noting that, since $P^{2}$ is proportional to $\mathscr{G}_{f}$, the coefficient of variation of $\mathscr{G}_{f}$ is about $\omega_{P} \sqrt{2}$ (as it follows by attributing the $\chi^{2}$-distribution to $\left.\mathscr{G}_{f}\right)$. Because $\tilde{\mathscr{G}}_{f}=\mathscr{G}_{f}+\left(\tilde{\mathscr{G}}_{f}-\mathscr{G}_{f}\right)$, we then have $2 \tilde{\omega}_{\mathrm{P}}^{2} \simeq 2 \omega_{\mathrm{P}}^{2}+\tilde{\omega}_{f}^{2}$, and substituting our previous estimate for $\omega_{P}$ we have 


$$
\begin{gathered}
\bar{\omega}_{\mathrm{P}} \simeq\left[\left(0.162^{2} / 2\right)+1.004 \omega_{t}^{2}+0.066^{2}\right]^{1 / 2} \\
=\left(0.132^{2}+1.004 \omega_{t}^{2}\right)^{1 / 2},
\end{gathered}
$$

provided that experimental values of $f_{t}^{\prime}$ and $E$ are substituted in Equation 27. If these are unavailable, one may further introduce in Equation 27 the well-known empirical approximate relations $f_{t}^{\prime}=6 \sqrt{f_{c}^{\prime}}$ and $E=57,000 \sqrt{f_{c}^{\prime}}$ where $f_{c}^{\prime}=$ standard cylindrical compression strength in psi. This, however, increases the error, causing that, roughly, $\tilde{\omega}_{P} \simeq\left[0.132^{2}+1.004\left(\omega_{t c}^{2}+\omega_{E c}^{2}+\omega_{c}^{2}\right)\right]^{1 / 2}, \quad$ where $\omega_{c}=$ coefficient of variation for compression strength, and $\omega_{t c}, \omega_{E c}=$ coefficients of variation of the deviations from the ratios $f_{t}^{\prime} / f_{c}^{\prime}$ and $E / f_{c}^{\prime}$ according to the empirical relations.

Equation 27 seems to succeed where previous attempts failed. The reason is, probably, that we use as a parameter the aggregate size, which becomes logical only when a crack band of finite width is considered; and secondly, that instead of trying to predict the apparent fracture energy values (corresponding to a certain point on the $R$-curve) including the initial ones, as measured e.g. by Naus, we interpret $\tilde{G}_{f}$ in Equation 27 strictly as the limiting fracture energy (the asympote of the $R$-curve) at which the fracture process zone becomes developed fully.

Equation 27 should be particularly useful for dam concretes. Their very large aggregate size would require too large fracture specimens, which has so far prevented measuring the fracture energy for these concretes directly. Yet, at the same time, dams belong to structures for which the use of fracture mechanics is needed most.

\section{CONCLUSIONS}

1. Fracture of a heterogeneous aggregate material such as concrete may be assumed to occur in the form of a blunt smeared crack band in which the material undergoes progressive microcracking characterized by a stress-strain relation that exhibits strain-softening. This hypothesis is justified by the macroscopic continuum smoothing of the randomly inhomogeneous rnicrostructure. At the same time, this hypothesis is rather convenient for finite element analysis, especially when the fracture path is not known in advance.

2. To model the formation and opening of microcracks normal to axis $z$ (partial cracking), it suffices to adjust only one term of the elastic compliance matrix, namely, the normal compliance for the $z$-direction. The adjustment factor, the inverse of which may be called the cracking parameter, varies from 1 at the start of microcracking (or of strain-softening) to $\infty$ when continuous cracks develop (complete cracking).

3. The inverse of the foregoing compliance matrix for the limiting case of complete cracking is the wellknown stiffness matrix of cracked concrete, as currently used. However this stiff ness matrix is more complicated since all of the terms of the elastic stiffness matrix require adjustment to model complete cracking.
Furthermore, partial cracking (microcracking) or strain-softening cannot be introduced into the stiffness matrix directly, i. e., other than through the compliance matrix and its inversion.

4. The present strain-softening formulation is a total stress-strain relation which is applicable only when the direction of the principal stress within the fracture process zone does not rotate significantly during the passage of the fracture front through a given station (the same assumption is implied in the $J$-integral approach).

5. The fracture energy is a function of the strainsoftening tangent modulus, the peak stress (tensile strength), and the width of the fracture process zone. One of the first two variables may alternatively be replaced by the area under the stress-strain diagram.

6. By virtue of modeling fracture through stressstrain relations, the triaxial effect of compression stresses parallel to the crack plane can be easily taken into account.

7. Fractures of arbitrary direction can be modeled as a zig-zag crack band in a square mesh of finite elements. A formula for the effective width of such a band is given.

8. The present theory is capable of satisfactorily representing essentially all fracture test data available in the literature, for various types and sizes of test specimens. The theory fits not only the maximum load data but also the $R$-curve (resistance curve) data and the data on strains near the crack front.

9. For the present theory, the optimum effective width of the crack band front is about three-times the maximum aggregate size. This value corresponds to the size of the representative volume used in statistical theory of heterogeneous media, and is about the minimum admissible from the viewpoint of continuum smoothing of the random inhomogeneities (aggregate).

10. Knowing the effective crack band width, it is possible to determine the fracture energy by measuring the uniaxial tensile stress-strain curve, including the strain-sof tening segment.

11. For computational purposes, the width of the element-wide band may be adjusted if the strainsoftening modulus is adjusted so as to preserve the same fracture energy. Objectivity of the model with regard to the analyst's choice of the element size is then verified. However, adjustment of the strain-softening modulus is possible only if the element size is less than $2 \mathscr{G}_{f} E / f_{i}^{\prime 2}$. Elements much larger than this can be used, but then a reduced strength limit and a sudden stress drop must be assumed.

12. The length of a fully developed fracture process zone is about 12-times the maximum aggregate size.

13. For very large structures (compared to aggregate size), the present theory assures that the energy consumed per unit crack band advancement equals the critical value of the energy release rate, and so the theory is, in the limit, equivalent to linear fracture 
mechanics. For small structures, the energy release rate for fracture propagation is less because the full fracture process zone cannot develop and the strength has influence, too. The values of fracture energy obtained by fitting test data with the present method differ from those obtained by other methods. These fracture energy values for various concretes can be predicted by an approximate formula from the tensile strength and the aggregate size. The value of the strain-softening modulus then follows also.

14. Based on a combined regression analysis of 17 test series from the literature, involving 68 data points, the coefficient of variation of the deviations of the normalized maximum load data from our theory is as low as $6.6 \%$, while for the linear fracture theory it is $27 \%$, and for the strength criterion $65 \%$. For $R$-curve test data, the standard error of $\log \mathscr{G}_{f}$ is $8 \%$ for our theory, as compared to $32 \%$ for the linear fracture theory. Thus, a significant improvement is achieved.

\section{ACKNOWLEDGMENT}

The work presented here was partly supported under National Science Foundation Grant No. CME8009050 to Northwestern University. During the final stage, partial support was received under AFOSR grant 830009. Thanks are due to Professor Surendra P. Shah for helpful comments on interpretations of test data. Mary Hill is thanked for her careful typing of the manuscript.

\section{APPENDIX I. PROOF OF THEOREM I}

The compliance relation $\underset{\varepsilon}{\varepsilon} \underset{\sim}{C} \underset{\sim}{\sigma}$ for uncracked concrete may be written in a partitioned form:

$\left\{\begin{array}{c}\varepsilon^{a} \\ \tilde{\varepsilon}_{z}\end{array}\right\}=\left[\begin{array}{cc}A & B \\ \tilde{B}^{T} & \tilde{C}_{33}\end{array}\right]\left\{\begin{array}{c}\sigma^{a} \\ \sigma_{z}\end{array}\right\}$.

Since $\underset{\sim}{C}=\underset{\sim}{D^{-1}}$, matrix $\underset{\sim}{\underset{\sim}{D}}$ must be a unit matrix, and so:

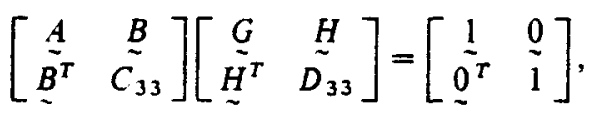

in which $\underline{1}=(2 \times 2)$ unit matrix. From this relation, $\underset{\sim}{A} \underset{\sim}{H}+\underset{\sim}{B} D_{33}=\underset{\sim}{0} \quad$ or $\quad \underset{\sim}{B}=-\underset{\sim}{A} \underset{\sim}{H} D_{33}^{-1}$. Also

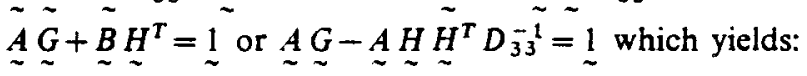

$\stackrel{A}{\sim}^{-1}=\underset{\sim}{G}-\underset{\sim}{H}{\underset{\sim}{H}}^{T} D_{33}^{-1}$.

Further we need to invert Equation 29. From this equation, $\varepsilon_{z}=\underline{B}^{T} \underline{\sigma}^{a}+C_{33} \mu^{-1} \sigma_{z}$ and substituting :

$$
\begin{aligned}
& \sigma^{a}={\underset{\sim}{A}}^{-1}\left(\varepsilon^{a}-B \sigma_{z}\right) \\
& \text { we may solve : } \\
& \sigma_{z}=\beta_{1}\left(\underset{\sim}{\varepsilon}=-\underline{\sim}^{T}{\underset{\sim}{A}}^{-1}{\underset{\sim}{q}}^{a}\right)
\end{aligned}
$$

with

$\beta_{1}=\left(C_{33} \mu^{-1}-{\underset{\sim}{B}}^{T}{\underset{\sim}{A}}^{-1} \underset{\sim}{B}\right)^{-1}$.

Substituting this again into the foregoing expression for $\varepsilon_{z}$, we find:

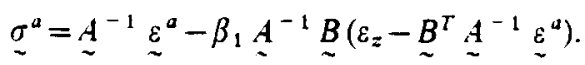

Together with the foregoing expression for $\sigma_{z}$, this may be written as:

$$
\begin{aligned}
& \left\{\begin{array}{c}
\sigma^{a} \\
\sigma_{z}
\end{array}\right\}=\underline{\sim}^{-1}(\mu) \underline{\varepsilon}
\end{aligned}
$$

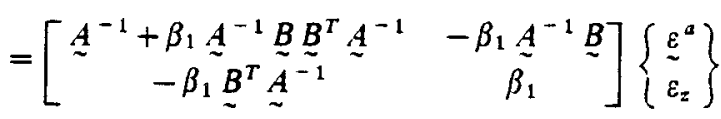

which is the inverted form of the compliance formulation. The case of fully cracked concrete is obtained for $\mu \rightarrow 0$. In this case $\beta_{1} \rightarrow 0$, and so:

$$
\underline{\sim}^{f r}=\lim _{\mu \rightarrow 0}{\underset{\sim}{C}}^{-1}(\mu)=\left[\begin{array}{ll}
A^{-1} & 0 \\
\tilde{0}^{T} & 0
\end{array}\right],
$$

in which ${\underset{\sim}{d r}}^{f r}$ is the stiffness matrix of fully cracked concrete. This matrix must coincide with the stiffness matrix in Equation 9. Equation 31 confirms that this is indeed so, which completes the proof.

\section{APPENDIX II. TENSORIAL GENERALIZATION AND SMOOTH STRESS-STRAIN CURVE}

The stress-strain relations which we developed are applicable only when the coordinate axes are oriented in principal stress directions. It is however possible to write Equation 3 in a general tensorial form applicable in any cartesian coordinates. For this purpose we need to define a new tensor, $\omega_{i j}$, the elements of which are in the principal coordinates as follows: $\omega_{i j}$ for $i \neq j$ is 0 ; $\omega_{i j}$ for $i=j$ is 1 if $\sigma_{i j}$ is the maximum principal stress and is tensile, and if $\varepsilon_{p}<\varepsilon_{i j} \leqslant \varepsilon_{0}$; while $\omega_{i j}$ for $i=j$ is 0 if all the foregoing conditions are not met. Obviously tensor $\omega_{i j}$ is the same as a uniaxial stress of unit value (and it of course transforms with coordinate rotations in the same manner as a uniaxial stress). As an example, for cracking in planes normal to $x_{3}$, the $6 \times 6$ form of $\omega_{i j}$ is:

$$
\omega_{i j}=\left[\begin{array}{llllll}
0 & 0 & 0 & 0 & 0 & 0 \\
0 & 0 & 0 & 0 & 0 & 0 \\
0 & 0 & 1 & 0 & 0 & 0 \\
0 & 0 & 0 & 0 & 0 & 0 \\
0 & 0 & 0 & 0 & 0 & 0 \\
0 & 0 & 0 & 0 & 0 & 0
\end{array}\right],
$$


The tangent compliance tensor from Equation 3 may now be generally represented as follows:

$C_{i j k m}=C_{i j k m}^{e l}-\frac{1}{C_{f}} \omega_{i k} \omega_{j m}$,

in which the presence of four subscripts indicates that $C_{i j k m}$ is now treated as a tensor (of 4th rank) rather than a matrix, and $C_{i j k m}^{e l}$ represents the elastic compliance tensor. Equation 3 may then be written in the general tensorial form:

$\varepsilon_{i j}=\left(C_{i j k m}^{e l}-\frac{1}{C_{f}} \omega_{i k} \omega_{j m}\right) \sigma_{k m}+\varepsilon_{0} \omega_{i j}$

By substituting 1, 2, 3 for $i$ and $j$, one can verify that, in principal coordinates, this equation reduces to Equation 3, which proves the correctness of Equation 35.

It is rather interesting to note that the order of indices $i k$-jm in the $\omega$-product cannot be obtained, with the help of the normality rule, from some loading surfaces. Indeed, a quadratic loading surface would always lead to terms of the type $\omega_{i j} \omega_{k m}$, as in plasticity. Thus, Equation 35 (or 6 or 12) cannot be obtained as a special case of plasticity or plastic-fracturing theory.

An alternative to Equation 35 which gives a smoothly curved stress-strain diagram was given in Reference [3].

Numerical calculations indicate that the representation of fracture test data is not very sensitive to the detailed shape of the uniaxial tensile stress-strain curve $\sigma_{z}=F\left(\varepsilon_{z}\right)$. Certain types of smooth curves could probably be used with equal success. One suitable curve is:

$c r_{z}=\mu E \varepsilon_{z}, \quad$ with $\quad \mu=e^{-k \varepsilon_{z}^{n}}$,

in which $n \simeq 2, k=\varepsilon_{p}^{-n} / n, \varepsilon_{p}=$ strain $\varepsilon$ at peak tensile stress $f_{i}^{\prime}$.

A smooth expression for $\mu$ seems to have both advantages and disadvantages. While it may be more realistic, and may also allow better convergence of iterations in step-by-step loading, it is unwieldy when the element size has to be larger than $w_{c}$ since the downward slope cannot be easily adjusted. Moreover, the question of fracture energy is more difficult since $S_{f} / w_{c}$ may be less than the area under the uniaxial tensile curve; see Reference [3].

Equation 37 may be obtained by integration of the evolution law:

$\frac{d \mu}{d \varepsilon_{z}}=k n \mu \varepsilon_{z}^{n-1}$.

This law, which is of a similar type as the damage evolution law used in continuous damage mechanics, can be directly applied in a finite element program for incremental loading (in conjunction with the differentiated form of Equation 6).

\section{APPENDIX III. INTERPRETATIONOF DIRECT TENSILE TEST}

The fracture formation may be regarded as a strainlocalization instability. In the direct tensile test, a state of uniform strain in the strain-softening range is stable (i. e., remains uniform) if, and only if, the following stability condition is satisfied:

$-E_{t}\left(\varepsilon_{z}\right)<\left[\frac{1}{E_{u}\left(\varepsilon_{z}\right)}\left(\frac{L}{w_{c}}-1\right)+\frac{1}{C w_{c}}\right]^{-1}$

$\left(L \geqq w_{c}\right)$,

or:

$$
-\bar{E}_{\mathrm{r}}\left(\varepsilon_{z}\right)<\left[\frac{1}{\overline{E_{u}\left(\varepsilon_{z}\right)}}\left(\frac{L}{w_{c}}-1\right)+\frac{1}{C w_{c}}\right]^{-1}
$$

(see Equations (51), (52) of Reference [3], or References [4] and [11]). Here $L=$ length of the tensile specimen, $C=$ stiffness constant of the loading frame; $E_{l}, E_{u}=$ tangent moduli for further loading (increasing $\varepsilon_{z}$ ) and for unloading (decreasing $\varepsilon_{z}$ ) from the same point $P$ on the strain-softening branch; $\bar{E}_{\mathrm{l}}, \bar{E}_{\mathrm{u}}=$ mean moduli for further loading and for unloading from point $P$, characterizing the slopes of the straight lines that average the curves of further loading and of unloading [3]. Inequality, (39) governs incremental stability (stability in the small) and inequality (40) governs stability in the large. If inequality (39) is violated, small strain localization into a segment of length $w_{c}$ suddenly occurs, however, complete failure does not occur unless inequality $(40)$ is also violated.

When the stress-strain diagram is bilinear and the unloading diagrams are straight lines with the same constant slope $E_{u}$, instability according to both inequalities (39) and (40) can happen either at the peak stress point or never. The situation is more involved when the actual, curved response diagrams are considered. As the strain $\varepsilon_{z}$ is increased, either inequality (39) or inequality (40) becomes first to be violated. If (39) is first, the strain-localization (failure) is gradual, static. If inequality (40) is first to be violated, and inequality (39) is still satisfied, failure cannot happen statically; however, if inequality (39) becomes satisfied later, failure happens dynamically, as an instability of snap-through type. This is what is usually observed in tensile tests. The precise point of instability and the nature of instability (static, or dynamic snapthrough) depends on the four functions $E\left(\varepsilon_{z}\right), \bar{E}\left(\varepsilon_{z}\right)$, $E_{u}\left(\varepsilon_{z}\right)$ and $\vec{E}\left(\varepsilon_{z}\right)$.

From (39) and (40) we see that instability is impossible if $C \rightarrow \infty$ (very stiff loading frame) and $L=w_{c}$. Under these two conditions the complete tensile stress-strain diagram can be always measured, and the strain will not localize within a portion of the specimen length (except for the statistical scatter of the microstrain). In practice, one might not know in advance the value of 
$w_{c}$ and the necessary frame stiffness $C$. However, as long as the measurements can be carried out one is certain that stability condition (40) holds, which means that no large strain localization can be taking place.

Consequently, the strain obtained from the elongation of the whole specimen is, essentially, the strain corresponding to the tensile stress-strain diagram even when $L>w_{c}$. Essentially so, because a small strain localization increment could have happened, unnoticed, statically, due to violation of inequality (39). However, such strain localizations can be only small since otherwise failure would have occurred.

If one accepts that a stress-strain relation, rather than a stress-separation displacement relation, is a basic material property, then the line crack models, such as that of Hillerborg, et al.'s, are equivalent to $w_{i} \rightarrow 0$. In that case, the right-hand side of Equation (39) is zero, which means that this stability condition is violated for any negative $E_{\mathrm{t}}$. This further means that strain-softening would be unobservable, would not exist. From the fact that it does exist and can be measured in uniaxial tension, we must therefore conclude that either (1) $w_{c}$ is finite and the line crack models are not quite realistic, or (2) a stress-separation displacement relation, rather than a stress-strain relation, is a basic material property.

\section{NOTATION}

$\begin{array}{ll}a_{0}, a, & \text { initial and current crack length, respectively; } \\ \Delta a, & \text { extension of crack; } \\ B, & \text { thickness of specimen; } \\ C, & \text { compliance matrix; } \\ C_{f}, & \text { slope of } \sigma_{z}-\varepsilon_{f} \text { curve; } \\ D, & \text { material stiff ness matrix; } \\ d_{a}, & \text { maximum aggregate size; } \\ E_{c}, & \text { Young's modulus of concrete; } \\ E_{t}, & \text { tangent strain-softening modulus; } \\ f_{l}^{\prime}, & \text { tensile strength of concrete; } \\ \mathscr{G}_{f}, & \text { strain energy release rate; } \\ \mathcal{G}_{f}, & \text { strain energy release rate based on linear } \\ H, & \text { theory; } \\ H_{1}, & \text { beam depth; } \\ K, & \text { finite element size; } \\ L, & \text { stress intensity factor; } \\ l_{f}, & \text { span of beam; } \\ M_{\max }, & \text { length of fracture process zone; } \\ M_{0}, & \text { maximum bending moment; } \\ P_{m}, & \text { bending moment for uncracked section } \\ P_{\max }, & \text { mased on strength; } \\ P_{t}, & \text { maximum applied load; } \\ P_{0}, & \text { theoretical } P_{\text {max }} ; \\ & \text { failure load based on strength criterion } \\ & \text { applied to uncracked cross section; } \\ & \end{array}$

s, standard error for vertical deviations from the regression line;

$w_{c}$, width of fracture process zone:

$x$, overall direction of zig-zag crack band;

$\delta_{f}, \quad$ crack opening;

$\omega$, coefficient of variation of the errors (vertical deviations from regression line);

$\varepsilon_{f}$, fracture strain (the additional strain caused by the opening of microcracks);

$\varepsilon_{x}, \varepsilon_{y}, \varepsilon_{z}, \quad$ principal strains;

$\varepsilon_{0}$, strain where the stress is reduced to zero;

$\sigma_{n}$, nominal maximum bending stress for the net cross section;

$\sigma_{x}, \sigma_{y}, \sigma_{z}$, principal stresses;

v. Poisson's ratio;

$\mu$ cracking parameter.

\section{REFERENCES}

[1] Asce State-of-the-Art Report on Finite element analysis of reinforced concrete, prepared by a Task Committee chaired by A. Nilson, Amer. Soc. of Civil Engrs., New York, 1982.

[2] BaRenblatt G. I. - The formation of equilibrium cracks during brittle fracture. General ideas and hypothesis. Axially-symmetric cracks, Prikladnaya Matematika i Mekhanika, Vol. 23, No. 3, 1959, pp. 434-444.

[3] BAŽAN] Z. P. - Crack band model for fracture of geomaterials, Proc., 4th Intern. Conf. on Numerical Methods in Geomechanics, held in Edmonton, Alberta, Canada, June 1982, ed. by Z. Eisenstein, Vol. 3.

[4] BAŽANT Z. P. - Instability, ductility and size effect in strain-softening concrete, $J$. of the Engineering Mechanics Division ASCE, Vol. 102, Apr. 1976, No. EM2, pp. 331-344, Paper 12042.

[4a] BAŽANT Z. P., - Mechanics of fracture and progressive cracking in concrete structures, to appear in "Fracture Mechanics applied to Concrete Structures", a volume in the series "Fracture Mechanics applied to Engineering Problems", ed. by G. C. Sin. publ. by Martinus Nijhoff Publishers, The Hagues. (b) Bazant Z. P.. Pfeiffer P. Preprints, 7 th Intern. Conference in Structural Mechanics in Reactor Technology (SMIRT), Chicago, Aug. 1983, Vol. $H$, in press.

[5] BaZ̈ant Z. P., Cedolin L. - Blunt crack band propagation in finite element analysis, Journal of the Engineering Mechanics Division, ASCE, Vol. 105, No. EM2, Proc. Paper 14529, April, 1979, pp. 297-315.

[6] BAZ̈ANT Z. P., CEDOLIN L. - Finite element modeling of crack band propagation, Journal of Structural Engineering, ASCE, Vol. 109, No. ST2, Jan. 1983, pp 69-82.

[7] BaŻaNT Z. P., CEdolin L. - Fracture mechanics of reinforced concrete, Journal of the Engineering Mechanics Division, ASCE, Vol. 106, No. EM6, Proc. Paper 15917 , December, 1980, pp. 1287-1306.

[8] Bažant Z. P., Gambarova P. G. - Rough cracks in reinforced concrete, Journal of the Structural Division, ASCE, Vol. 106, No. ST4, Paper No. 15330, A pril, 1980, pp. $819-842$.

[9] BAŽANT Z. P., KIM S. S. - Plastic-fracturing theory for concrete, Journal of the Engineering Mechanics Division, ASCE. Vol. 105, No. EM3, Proc. Paper 14653, June, 1979. pp. $407-428$. 
[10] BAŻANT Z. P., OH B. H. - Concrete fracture via stressstrain relations, Report No. $81-10 / 665 \mathrm{c}$, Center for Concrete and Geomaterials, Technological Institute, Northwestern University, Evanston, Ill., Oct. 1981.

[11] Bażant Z. P., Panula L. - Statistical stability effects in concrete failure, J. of the Engineering Mechanics Division, ASCE, Vol. 104, Oct. 1978, No. EM5, pp. 1195-1212, Paper 14074.

[12] BAŻANT Z. P., TsubakI T. - Slip-dilatancy model for cracked reinforced concrete, Journal of the Structural Division, ASCE, Vol. 106, No. ST9, Paper No. 15704, September, 1980, pp. 1947-1966.

[13] BRown J. H. - Measuring the fracture toughness of cement paste and mortar, Magazine of Concrete Research, Vol. 24. No. 81. December, 1972. pp. 185-196.

[14] CARPINTERI A. - Experimental determination of fracture toughness parameters $K_{I C}$ and $J_{I C}$ for aggregative materials, Advances in Fracture Research," (Proc., 5th International Conference on Fracture, Cannes, France, 1981), Ed. by D. François, Vol. 4, pp. 1491-1498.

[15] Carpinteri A. - Static and energetic fracture parameters for rocks and concretes, Report, Istituto di Scienza delle Costruzioni-Ingegneria, University of Bologna, Italy, 1980.

[16] Cedolin L., Bazant Z. P. - Effect of finite element choice in blunt crack band analysis, Computer Methods in Applied Mechanics and Engineering, Vol. 24, No. 3, December 1980, pp. 305-316.

[17] Entov V. M., Yagust V. I. - Experimental investigation of laws governing quasi-static development of macrocracks in concrete, Mechanics of Solids (translation from Russian), Vol. 10, No. 4, 1975, pp. 87-95.

[18] Evans R. H., Marathe M. S. - Microcracking and stress-strain curves for concrete in tension, Materiaux et Constructions, Vol. 1, No. 1, 1968, pp. 61-64.

[19] Gjorv O. E., Sorensen S. I., Arnesen A. - Notch sensitivity and fracture toughness of concrete, Cement and Concrete Research, Vol. 7, 1977, pp. 333-344.

[20] Hillerborg A., Modeer M., Petersson P. E. - Analysis of crack formation and crack growth in concrete by means of fracture mechanics and finite elements, Cement and Concrete Research, Vol. 6, 1976, pp. 773-782.

[21] Huang C. M. J. - Finite element and experimental studies of stress intensity factors for concrete beams, Thesis Submitted in Partial Fulfillment of the Requirements for the Degree of Doctor of Philosophy, Kansas State University, Kansas, 1981.

[22] IsidA M. - Elastic analysis of cracks and stress intensity factors, Baifukan Publishing Co., Japan, 1976.

[23] JANSON J., HuLT J. - Fracture mechanics and damage mechanics-a combined approach, Journal de Mécanique appliquée, Vol. 1, No. 1, 1977, pp. 69-84.

[24] Kachanov L. M. - Time of rupture process under creep conditions, Izv. Akad. Nauk, SSSR. Otd. Tekh. Nauk, No. 8, 1958, pp. 26-31.

[25] KaPLAN M. F. - Crack propagation and the fracture of concrete, American Concrete Institute Journal, Vol. 58, No. 11, November 1961.

[26] Kesler C. E., Naus D. J., LotT J. L. - Fracture mechanics-Its applicability to concrete, International Conference on the Mechanical Behavior of Materials, Kyoto, August 1971.

[27] Kfouri A. P., Miller K. J. - Stress displacement, line integral and closure energy determinations of crack tip stress intensity factors, Int. Journal of Pres. Ves. and Piping, Vol. 2, No. 3, July 1974, pp. 179-191.

[28] KfourI A. P., RICE J. R. - Elastic/plastic separation energy rate for crack advance in finite growth steps, in "Fracture 1977" (Proc. of the 4th Intern. Conf. on Fracture, held in Waterloo. Ontario, June 1977), ed. by
D. M. R. Taplin, University of Waterloo Press 1977 , Vol. 1, pp. 43-59.

[29] KNauss W. C. - On the steady propagation of a crack in a viscoelastic sheet; experiments and analysis, reprinted from The Deformation in fracture of high polymers, Ed. by H. H. Kausch, Pub. Plenum Press, 1974, pp. 501-541.

[30] KNotT J. F. - Fundamentals of fracture mechanics, Butterworths, London, England, 1973.

[31] Kupfer H. B., Gerstle K. H. - Behavior of concrete under biaxial stress, Journal of the Engineering Mechanics Division, ASCE, Vol. 99, No. EM4, Proc. Paper 9917, August, 1973, pp. 853-866.

[32] Liv T. C. Y., Nilson A. H., Slate F. O. - Biaxial stress-strain relations for concrete, Journal of the Structural Division, ASCE, Vol. 98, No. ST5, Proc. Paper 8905, May, 1972, pp. 1025-1034.

[33] Loland K. E. - Continuous damage model for loadresponse estimation of concrete, Cement and Concrete Research. Vol. 10, 1980, pp. 395-402.

[34] LORRAIN M. - On the application of the damage theory to fracture mechanics of concrete, A State-of-the-Art Report, Civil Engineering Department, I.N.S.A., 31077 Toulouse, Cedex, France.

[35] Marchertas A. H., Belytschko T. B., Bazant Z. P. Transient analysis of LMFBR reinforced/prestressed concrete containment, Trans., 5th Intern. Conf. on Structural Mechanics in Reactor Rechnology, West Berlin, Aug. 1979, Vol. H., Paper H8/1, ed. by T. A. Jaeger and B. A. Boley, publ. by North Holland.

[36] MazArs J. - Mechanical damage and fracture of concrete structures, 5th International Conference on Fracture, Edited by D. François, Cannes, France, 29 March-3 A pril. 1981. Vol. 4. pp. 1499-1506.

[37] Mivisiss S. Dinuowis. - A proliminary SEM satedy of crack propagation in mortar, Cement and Concrete Research, Vol. 10, 1980, pp. 509-519.

[38] Mindess S., Lawrence F. V., Kesler C. E. - The Jintegral as a fracture criterion for fiber reinforced concrete, Cement and Concrete Research, Vol. 7, 1977, pp. $731-742$.

[39] NAus D. J. - Applicability of linear-plastic fracture mechanics to Portland cement concretes, Thesis Submitted in Partial Fulfillment of the Requirements for the Degree of Doctor of Philosophy, University of Illinois at Urbana-Champaign. 1971.

[40] PARIS P. C. - Fracture mechanics in the elastic plastic regime, Flaw Growth and Fatigue, ASTM Special Techn. Publ. 631, Amer. Soc. for Testing Materials, Philadelphia, 1977, pp. 3-27.

[41] Petersson P. E. - Fracture energy of concrete: Method of determination, Cement and Concrete Research, Vol. 10, 1980, pp. 78-89, and "Fracture Energy of Concrete: Practical Performance and Experimental Results," Cement and Concrete Research. Vol. 10, 1980, pp. 91-10!.

[42] RiCE J. R. - The localization of plastic deformation. Preprints of the 14th IUTAM Congress (Int. Union of Theor. and Appl. Mech.), held in Delft, Netherlands, in 1976, Edited by W. T. Koiter, North Holland Publishing Co., Amsterdam, pp. 207-220.

[43] Saouma V. E., Ingraffea A. R., Catalano D. M. Fracture toughness of concrete- $K_{I C}$ revisited, Journal of the Engineering Mechanics Division, Vol. 109, $\mathrm{N}^{\circ} \mathrm{EMG}$, Dec. 1982, pp. 1152-1166.

[44] Shah S. P., McGarRy F. J. - Griffith fracture criterion and concrete, Journal of the Engineering Mechanics Division, ASCE, Vol. 97, No. EM6, Proc. Paper 8597. December. 1971. pp. 1663-1676.

[45] Sok C., Baron J.. Françors D. - Mécanique de la rupture appliquée au béton hydraulique, Cement and Concrete Research. Vol. 9. 1979. pp. 641-648. 
[46] Suidan M., Schnosrich W. C. - Finite element analysis of reinforced concrete, Journal of the Structural Division, ASCE, Vol. 99, No. ST10, Proc. Paper 10081, October 1973, pp. 2109-2122.

[47] Swartz S. E., Hu K. K., Fartash M., Huang C. M. J. Stress intensity factors for plain concrete in bending. Prenotched versus precracked beams. Report, Department of Civil Engineering, Kansas State University, Kansas, 1981.

[48] TADa H., Paris P. C., IRwin G. R. - The stress analysis of cracks handbook, Del Research Corp., Hellertown, Pa., 1973.
[49] WALSH P. F. - Fracture of plain concrete, The Indian concrete Journal, Vol. 46, No. 11, November 1979, pp. 469,470 and 476 .

[50] Wecharatana M., Shah S. P. - Resistance to crack growth in Portland cement composites, Report, Department of Material Engineering, University of Illinois at Chicago Circle, Chicago, Illinois, November 1980.

[51] WNUK M. P. - Quasi-static extension of a tensile crack contained in viscoelastic plastic solid, Journal of Applied Mechanics, ASME, Vol. 41, 1974, No. 1, pp. 234-248.

\section{RÉSUMÉ}

Théorie de bande de fissuration pour la rupture du béton. - On présente une théorie de la rupture pour un matériau hétérogène à granulats qui montre une déformation avec radoucissement causé par microfissuration et qui renferme des granulats dont les dimensions peuvent n'être pas petites par rapport à celles de la structure. On ne considere que le mode I. La rupture est modélisée comme une bande de microfissures parallèles à front obrus, ce qui se justifie par le caractère aléatoire de la microfissuration. On déduit des relations simples de contrainte/déformation triaxiales qui modélisent des déformations à radoucissement et décrivent leffet de la microfissuration graduelle dans la zone de fissures parallèles. On démontre qu'il est plus facile d'utiliser les matrices de compliance que de rigidité et qu'il suffit d'ajuster un simple élément diagonal de la matrice de compliance. On verra qu'à la limite cette matrice pour une fissuration continue est identique a l'inverse de la bien connue matrice de rigidité pour un matériau parfaitement fissuré. Les propriétés de rupture du matériau ne sont caractérisées que par trois paramètres: énergie de rupture, limite de résistance uniaxiale et largeur de la bande de fissuration (zone où intervient la rupture), le module de radoucissement de déformation étant une fonction de ces paramètres. On donne aussi une méthode pour déterminer l'énergie de rupture d'après les relations complètes contrainte/déformation mesurées. On peut prendre en compte les effets sur la rupture des contraintes triaxiales.

La théorie se vérifie au moyen de comparaisons avec les nombreux résultats expérimentaux publiés. On obtient de bonnes concordances tant pour les données de charges maximales que pour les courbes de résistance; les valeurs des trois paramètres de matériau en jeu, soit lénergie de rupture, la résistance, la largeur du front de la bande fissuration sont déterminées d'après les résultats d'essai. Il apparait que la valeur optimale du dernier paramètre est d'environ trois fois la dimension d'un granulat, ce qui se justifie également comme le minimum acceptable pour une modélisation d'un milieu homogène continu. On indique aussi la méthode pour utiliser la théorie dans un code d'éléments finis et les règles pour atteindre a Tobjectivité des résultats à légard du choix de la dimension d'un élément par lanalyste. Enfin, on dérive une formule simple de prévision de lénergie de rupture d'après la résistance en traction et la dimension du granulat, ainsi que du module datténuation de déformation. L'analyse statistique des erreurs met en évidence un progrès radical sur la théorie de la rupture linéaire, ainsi que sur la théorie de la résistance. Ainsi établit-on solidement la possibilité d' appliquer au béton la mécanique de la rupture. 